\title{
Biphasic effects of IL-27 during Staphylococcus aureus implant-associated osteomyelitis in mice
}

${ }^{a}$ Center for Musculoskeletal Research, University of Rochester Medical Center, Rochester, NY, USA

bepartment of Environmental Medicine, University of Rochester School of Medicine and Dentistry,

10 Rochester, NY, USA

'Department of Orthopaedic Surgery, Virginia Commonwealth University, Richmond, VA, USA

${ }^{\mathrm{d} D e p a r t m e n t}$ of Orthopaedics, University of Rochester Medical Center, Rochester, NY, USA

eDepartment of Pathology and Laboratory Medicine, University of Rochester Medical Center,

14 Rochester, NY, USA

\section{\#Corresponding Author:}

Gowrishankar Muthukrishnan, Ph.D.

18 The Center for Musculoskeletal Research

19 Department of Orthopaedics

University of Rochester Medical Center

601 Elmwood Avenue, Box 665

Rochester, NY 14642

Phone: 585-273-5632, Fax: 585-276-2177

E-mail: Gowri_Shankar@URMC.Rochester.edu

Conflict of interest statement: The authors have declared that no conflict of interest exists.

Running title: Biphasic effects of IL-27 during S. aureus osteomyelitis

Keywords: interleukin-27, S. aureus, osteomyelitis, staphylococcal abscess, osteolysis, host-pathogen interactions 


\section{Abstract}

34 Interleukin-27 is a pleiotropic cytokine whose reported functions during bacterial infections are debated as an area of active research. To address this, we investigated the role of IL-27 signaling during Staphylococcus aureus osteomyelitis. Clinically, we observed elevated serum IL-27 levels (20-fold higher, $\mathrm{p}<0.05$ ) in patients with $S$. aureus osteomyelitis compared to uninfected patients undergoing elective total joint replacement. Remarkably, IL-27 serum levels immediately following septic death were 60 -fold higher vs. uninfected patients $(p<0.05)$, suggesting that IL-27 may be a biomarker of endstage infection and/or cytokine storm. To test this, we hypothesized that IL-27 mediates bacterial clearance during the acute phase of $S$. aureus osteomyelitis, and subsequently suppresses inflammation to prevent cytokine storm and osteolysis during chronic infection. In mice, we observed that systemic IL-27 delivery by a recombinant adeno-associated viral vector (rAAV-IL-27) ameliorates surgical site soft tissue infection and peri-implant bone loss during the establishment of implant-associated S. aureus osteomyelitis. This effect was not observed in IL-27 receptor $\alpha$ knock-out mice, suggesting a direct role of IL-27/IL-27R signaling on immune and bone cell functions. Examination of IL-27-mediated immune responses via transcriptome analyses of infected tibiae demonstrated that IL-27 is a biphasic cytokine with IL-27/IL-27R activating immunostimulatory responses including Th17, IL-2, TLR, and iNOS signaling early, and subsequently suppressing these pathways during chronic infection. Ex vivo confirmation using murine macrophages revealed that IL-27 co-stimulates TLR signaling to increase the

51 production of nitric oxide, and immunomodulatory cytokines such as IL-10, IL-21, IL-31, and TNF- $\beta$, 52 but is not a chemokine. 


\section{Author Summary}

54 Staphylococcus aureus is the most common pathogen in orthopaedic infections, and hard-to-treat

55 (MRSA) strains cause $>50 \%$ of these infections. Thus, there is an urgent need to develop

56 immunotherapies to treat these life-threatening S. aureus infections. Currently, the role of

57 multifunctional IL-27 on S. aureus osteomyelitis is unknown. In a clinical study, we observed that IL-27

58 is an important biomarker for identifying $S$. aureus osteomyelitis patients, and that elevated serum IL-27

59 levels correlated with adverse clinical outcomes, such as septic death. In our efforts to uncover the

60 underlying mechanisms, we reveal that IL-27 is a biphasic cytokine, activating proinflammatory

61 immune pathways, including Th17 responses, early during acute $S$. aureus osteomyelitis, and

62 subsequently repressing them during the chronic phase to prevent cytokine storm and bone damage.

63 These results indicate that immune modulation of IL-27/IL-27R signaling could be a viable therapeutic

64 strategy in mitigating $S$. aureus osteomyelitis. 


\section{Introduction}

66 Deep bone infections continue to be the bane of orthopaedic surgery, with infection rates essentially remaining at $1-2 \%$ for elective surgery over the past 50 years, despite significant medical advances [13]. Staphylococcus aureus is the major pathogen in orthopaedic infections. It is responsible for causing 10,000-20,000 prosthetic joint infections (PJI) annually in the United States alone $[4,5]$ and 30-42\% of fracture-related infections (FRI) [6, 7]. Unfortunately, these difficult-to-treat S. aureus bone infections are associated with poor clinical outcomes and high recurrence rates following revision surgery $[8,9]$. With increasing methicillin-resistant S. aureus (MRSA) osteomyelitis incidence rates, and emerging strains with pan-resistance $[10,11]$, there is an urgent need for novel immunotherapies to supplement existing antibiotic therapies. catastrophic outcome of osteomyelitis is death due to sepsis and multiple organ failure $[12,13]$. The mechanisms behind $S$. aureus osteomyelitis-induced sepsis are largely unknown. Interestingly, several studies have reported elevated serum IL-27 levels during sepsis, suggesting that IL-27 could potentially be a diagnostic biomarker of sepsis [14-19]. IL-27 is a heterodimeric cytokine belonging to the IL-12 cytokine family and is mainly produced by antigen presenting cells such as macrophages, monocytes, and dendritic cells $[20,21]$. It is composed of IL-27p28 and EBI3 subunits, and signals through a heterodimeric cell surface receptor composed of IL-27 receptor $\alpha($ IL-27R $\alpha)$ and gp130 [22, 23]. Like IL-12, it signals mainly through the JAK-STAT intracellular pathway and plays a central role in multiple immune regulation activities. It downregulates Th17 differentiation, stimulates regulatory T cell

85 formation, and directly modifies CD4+ T cell effector functions to induce anti-inflammatory IL-10 [20,

$8621,24,25]$. Studies involving cecal ligation and puncture (CLP)-induced bacterial sepsis and S. aureus

87 pneumonia following influenza demonstrated that IL-27 regulates enhanced susceptibility to infection 
importance of IL-27 in immune suppression. On the other hand, IL-27 has been reported to promote proliferation and differentiation of hematopoietic stem cells [28], increase production of

91 proinflammatory cytokines by monocytes [29, 30], and induce Th1 differentiation [31]. Currently, the

92 role of IL-27 in host immunity during S. aureus osteomyelitis is unknown. Here, we tested the

93 hypothesis that IL-27 is a biphasic cytokine that enhances bacteria killing via promoting inflammation

94 early during acute $S$. aureus osteomyelitis, and subsequently suppresses inflammation during chronic

is induced in patients with $S$. aureus osteomyelitis, and elevated serum IL-27 correlated with septic

death in these patients. Examining IL-27's role in mice revealed that this cytokine is crucial for carefully osteomyelitis.

\section{Results}

\section{S. aureus infection induces IL-27 secretion in patients and in mice}

103 To better understand host immune responses against $S$. aureus osteomyelitis, we analyzed sera from

104 healthy people, orthopaedic patients with culture-confirmed $S$. aureus bone infections, and patients who 105 died from septic $S$. aureus osteomyelitis. Serum IL-27 levels were significantly elevated in infected 106 patients compared to uninfected individuals (20-fold higher, $\mathrm{p}<0.05)$. Remarkably, IL-27 levels

107 immediately following septic death were 60-fold higher (Fig. 1A, p $<0.05$ ), suggesting that IL-27 could

108 be an essential biomarker for S. aureus osteomyelitis-induced septic death. Indeed, formal analyses of 109 IL-27 as a diagnostic biomarker using receiver operator characteristic (ROC) curve analysis revealed a 110 high area under the curve (AUC) of 0.922 (Fig. 1B, $\mathrm{p}<0.0001$ ). We also evaluated whether S. aureus

111 infection directly induces IL-27 production in murine macrophages in vitro. Interestingly, in both RAW 112264.7 macrophages and murine bone marrow-derived macrophages, S. aureus induced significant IL-27 
113 secretion 24 hours post infection in M0, M1, and M2 murine macrophages (Fig. 1C-D, p<0.05).

114 Collectively, these data indicate an important role for IL-27 in host immunity against S. aureus

115 infections.

116 Systemic IL-27 delivery inhibits draining abscess formation and bone osteolysis during 117 establishment of $\boldsymbol{S}$. aureus osteomyelitis

118 Having established an association between IL-27 and S. aureus osteomyelitis in patients and mice, we 119 next examined if IL-27 mediates bacterial clearance during S. aureus osteomyelitis using our well120 established murine model of osteomyelitis [32-36]. Mice were challenged with bioluminescent MRSA 121 (USA300 LAC::lux ) via transtibial implantation of a contaminated stainless-steel implant following 122 intramuscular injection of rAAV-IL-27 or adeno-associated virus expressing recombinant GFP (rAAV123 GFP, control). Before the in vivo infection experiment, we confirmed exogenous IL-27 expression in 124 mouse sera out to day 24 following intramuscular injection of rAAV-IL-27 (Fig. 2A). While rAAV-IL12527 treatment did not show an effect on in vivo $S$. aureus growth as assessed by bioluminescent intensity 126 (BLI) (Fig. 2B), rAAV-IL-27 treated mice showed greater body weight recovery following septic127 surgery compared to rAAV-GFP treated animals (Fig. 2C). Remarkably, rAAV-IL-27 treated animals 128 showed much smaller draining abscess formation at the site of bone infection (Fig. 2D). Ex vivo CFU 129 analyses confirmed that the bacterial load in surgical site soft tissues was significantly lower in rAAV130 IL-27 treated mice (Fig. 2E). Moreover, high-resolution $\mu \mathrm{CT}$ demonstrated that peri-implant osteolysis 131 was decreased in mice treated with rAAV-IL-27 compared to rAAV-GFP treated animals (Fig. 2F).

132 These results demonstrate that IL-27 affects abscess formation and bone osteolysis. Interestingly, CFU 133 quantification on the implants revealed similar bacterial loads between groups suggesting that systemic 134 IL-27 treatment does not affect biofilm formation on the implant. Indeed, scanning electron microscopy 135 (SEM) interrogation confirmed these findings (Supplemental Fig. 1).

136 Systemic IL-27 effects on $S$. aureus implant associated osteomyelitis in IL-27R $\boldsymbol{\alpha}^{-/-}$mice 
137 Two possible scenarios can lead to the observed suppression of $S$. aureus SACs and reduced bone

138 osteolysis at the surgical site. IL-27 could be a chemokine attracting myeloid cells to the site of $S$.

139 aureus infection. Alternatively, IL-27/IL-27R signaling pathway could extrinsically be inducing

140 chemotaxis of innate immune cells to the infection site. First, we examined if IL-27 is chemotactic of

141 myeloid cells. In vitro chemotaxis assay using granulocytic HL-60 cells revealed that IL-27 did not

142 promote migration of granulocytes through the Boyden chambers (Supplemental Fig. 2). IL-27 was

143 also not chemotactic of primary bone marrow-derived macrophages (data not shown). Next, to test

144 whether IL-27/IL-27R signaling was inducing chemotaxis of immune cells to cause the observed

145 phenotype, we repeated the in vivo $S$. aureus osteomyelitis experiments using IL-27 receptor $\alpha$ knock

146 out (IL-27R $\left.\alpha^{-/}\right)$mice. At 14 days post infection, body weight changes (Fig. 3A) and BLI (Fig. 3B) were

147 similar between IL-27R $\alpha^{-/-}$mice treated with rAAV-IL-27 or rAAV-GFP. Most interestingly, ex vivo

148 CFU on the implants, surgical site soft tissues, and tibia were similar in IL-27R $\alpha^{-/-}$mice (Fig. 3D).

149 Furthermore, no difference was detected in draining abscess formation on these implants (Fig. 3C) and

150 gross assessment of peri-implant osteolysis (data not shown) between groups. These data indicate that

151 the effects of rAAV-IL-27 on S. aureus osteomyelitis in WT mice were due to IL-27/IL-27R signaling.

152 Identification of systemic IL-27 affected pathways during the establishment of implant-associated

153 osteomyelitis

154 Next, we sought to elucidate the mechanism of IL-27/ IL-27R signaling effects on S. aureus

155 osteomyelitis via unbiased gene expression studies. MRSA-infected mouse tibiae from rAAV-IL-27-

156 and rAAV-GFP-treated groups were harvested on days 1, 3, 7, and 14 post-septic surgery and subjected

157 to bulk RNA sequencing. The number of differentially (up-regulated or down-regulated) expressed

158 genes (DEGs) on each day are shown in Fig. 4B. Venn diagram analyses of DEGs revealed $I L-27$,

159 prostaglandin E synthase (PTGES), and sodium/myo-inositol cotransporter (SLC5A3) to be the common

160 overlapping nodal points across all time points (Fig. 4C). Expectedly, IL-27 expression in the infected 
161 tibia was significantly up-regulated in mice treated with rAAV-IL-27 compared to rAAV-GFP at all

162 time points (Fig. 4D), suggesting a positive feedback effect [37].

enriched between rAAV-IL-27 and rAAV-GFP treated animals (Fig. 4E). Examination of enriched

pathways involved in innate and adaptive immunity revealed that pro-inflammatory immune pathways

including IL-23 signaling pathway, Th17 activating pathway, IL-17 signaling, and IL-2 signaling were

activated in rAAV-IL-27 treated mice during the acute phase of $S$. aureus osteomyelitis (day 1 post-

surgery) compared to rAAV-GFP treated animals. Interestingly, these pathways were suppressed at later

indicate that IL-27 could be a biphasic cytokine, which activates pro-inflammatory immune pathways

early upon $S$. aureus infection and suppresses them late to prevent tissue damage and cytokine storm.

\section{IL-27-mediated induction of pro-inflammatory cytokines early during $S$. aureus osteomyelitis and}

\section{their down-regulation during chronic infection}

RNAseq analyses revealed that genes associated with IL-23 signaling (Fig. 5A) and Th17 activation

pathway (Fig. 5B) were significantly were up-regulated in mice treated with rAAV-IL-27 on day 1 post-

surgery, compared to rAAV-GFP animals. These genes include $I L 17 A, I L-17 F, I L-21$, and $I L 12 B$. We

confirmed that IL-27-pretreated murine macrophages induce moderate production of pro-inflammatory

cytokines such as IL-21, IL-31, and TNF- $\beta$ early in response to $S$. aureus infection (Table 1). Of note,

anti-inflammatory cytokine IL-10 was also modestly up-regulated in these macrophages suggesting a

pleiotropic nature for IL-27. Remarkably, pro-inflammatory cytokine coding genes such as IL17A,

$181 I L 12 A, T N F$, and $I L-6$ were down-regulated later at day 14 during the chronic phase of infection (Fig.

182 5A-B). Utilizing the DEG data, we also assessed the top regulatory networks in IPA for these genes to

183 provide further insight into the effects of differential gene expression in our dataset (Supplemental

184 Table 1). Our analyses indicated that regulatory genes such as HSP90B1 and EGR2, up-regulated pro-

185 inflammatory cytokine-coding genes $I L 21, I L 17 A, I L 12 B, I L 17 F$, and RORC in rAAV-IL-27 treated 
mice. $R O R C$ encode the Th17 master transcription factor ROR $\gamma \mathrm{t}$ [38]. Additionally, transcriptome

analyses revealed that immunostimulatory genes associated with Toll-like receptor (TLR) (Fig. 5C) and

iNOS (Fig. 5D) signaling pathways were suppressed at later stages of $S$. aureus infection. However, their expression levels during the early infection phase (day 1) were equivocal. Indeed, we confirmed that combination of IL-27 and TLR agonist lipopolysaccharide (LPS) stimulation increased nitric oxide

$191\left(\mathrm{NO}^{-}\right)$production in primary macrophages, suggesting a co-immunostimulatory effect on TLR signaling suppressing them late to prevent tissue damage.

\section{rAAV-IL-27 treatment inhibits osteoclast formation during implant-associated osteomyelitis}

animals on days 3, 7, and 14 (Fig. 4E, 6A). Histopathology confirmed the suppression effect of IL-27 on

201 osteoclasts (Fig. 6B), where systemic IL-27 induced significantly less osteoclast activation in trabecular 202 bone (Fig. 6C).

\section{Discussion}

205 Cytokines, including IL-27, are central to mounting an immune response during infection, and 206 elucidation of IL-27 functions throughout infection is essential to our understanding of protective vs. 207 susceptible host immunity [20]. In this study, we examined the role of IL-27 during S. aureus 208 osteomyelitis as clinical studies revealed elevated serum IL-27 levels in patients with S. aureus bone 209 infections. In mice, we demonstrated that IL-27/IL-27R signaling mediates bacterial clearance during 
210 the acute phase of $S$. aureus osteomyelitis, and suppresses subsequent inflammation to prevent cytokine

211 storm and bone osteolysis during chronic infection. osteomyelitis in patients $(\mathrm{AUC}=0.922)$. Previous studies have shown that serum IL-27 levels are

214 elevated in sepsis patients, indicating its potential as a diagnostic biomarker of sepsis [14-18, 39]. A

215 single-center prospective study demonstrated that serum IL-27 levels could be utilized to achieve AUCs 216 of 0.75 in patients with sepsis [16]. Though IL-27 levels immediately following septic death were 60217 fold higher in patients compared to uninfected patients, we couldn't perform AUC calculations due to 218 the low number of septic death patients. Nonetheless, our study indicates that IL-27 could be a 219 diagnostic marker of $S$. aureus osteomyelitis, and more extensive patient cohort studies are required to 220 formally assess its diagnostic potential. Systemic IL-27 delivery led to amelioration of surgical site soft tissue infection and peri-implant bone loss during the establishment of $S$. aureus osteomyelitis. However, the bacterial loads on the implant or bone were not affected by IL-27 delivery underscoring the ability of $S$. aureus to invade deep within the immune-privileged environment of bone [40]. Interestingly, reduction in abscess formation and bone osteolysis was not observed in IL-27 receptor $\alpha$ knock-out mice, suggesting a direct role of IL-

27/IL-27R signaling on immune and bone cell functions. Similarly, Wang et al. showed that

230 murine model [42]. Collectively, these studies highlight the diverse effects of IL-27 on various bacterial 231 infections. 
235 contributes to time-dependent changes in host immunity from acute to chronic $S$. aureus osteomyelitis.

236 A recent study, using a murine intra-femur osteomyelitis model, demonstrated similar time-dependent

237 changes in host response during S. aureus osteomyelitis using gene expression analyses [43]. We also

238 revealed that IL-23, Th17 activation, IL-17 signaling, and pro-inflammatory IL-21 were up-regulated

239 during early $S$. aureus infection. Collectively, these pathways contribute to the expansion of Th17 cells

240 and induction of Th17-mediated immunity, which are crucial to host defense against bacterial infections

$241[44,45]$. However, excessive or prolonged Th17 responses due to chronic infection cause tissue damage

242 and autoimmune diseases [46-48]. In addition to thwarting immune responses, we observed that

243 systemic IL-27 administration suppresses inflammatory osteoclasts to prevent bone damage during the

244 chronic phase of S. aureus osteomyelitis. This is consistent with the known effects of IL-27 on inhibition

245 of osteoclastogenesis [49-52]. Collectively, these studies add to the growing body of IL-27 literature

246 with reported pro-inflammatory and anti-inflammatory effects on various immune cells [24, 29, 30, 53 -

$24758]$.

osteomyelitis (Fig. 7). IL-27 promotes host immune reaction against S. aureus osteomyelitis by

Here, we propose a schematic model of IL-27-mediated immune homeostasis during S. aureus

254 53-55] and osteoclastogenesis [49-52] to prevent cytokine storm and osteolysis. The proposed IL-27

255 mediated immune homeostasis model is preliminary, and warrants several further investigations. Firstly,

256 we need to examine the immune cell repertoire in the bone marrow niche that causes IL-27/IL-27R-

257 mediated effects during S. aureus osteomyelitis over time. Secondly, we need to understand IL-27's role

258 in preventing cytokine storm and internal organ tissue damage during chronic S. aureus osteomyelitis in

259 a more relevant osteomyelitis sepsis murine model. Humanized mice, which are more susceptible to 
260 MRSA osteomyelitis-induced sepsis, may be better suited for these studies [59]. Finally, we need to

261 assess how systemic IL-27 inhibits bone osteolysis by suppressing RANKL-mediated

262 osteoclastogenesis. These studies will further our understanding of IL-27/IL-27R signaling during $S$.

263 aureus osteomyelitis.

Materials and Methods

$\underline{\text { Bacterial strains }}$

267 Methicillin-resistant S. aureus (USA300 LAC) was used for all in vitro experiments, and a

268 bioluminescent strain of USA300 (USA300 LAC::1ux) was used for all in vivo experiments as

269 previously described [32-34, 36, 59].

270 Ethics Statement and Patient Enrollment

271 Serum samples were collected from $S$. aureus osteomyelitis patients $(n=23)$ and uninfected patients

272 undergoing elective total joint replacement $(n=10)$. Additionally, serum samples were collected

273 immediately post-mortem in patients that succumbed to $S$. aureus osteomyelitis sepsis (n=5). All

274 recruited patients were either part of an international biospecimen registry (AO Trauma Clinical Priority

275 Program (CPP) Bone Infection Registry) [60] or clinical studies conducted at the Virginia

276 Commonwealth University. Patients were recruited with local IRB approvals at various institutions, and

277 patient information was collected in a REDCap database managed by AO Trauma and VCU data

278 management administrators. Laboratory investigators had access only to de-identified clinical data,

279 which was provided on request by the data management teams. All ex vivo and in vivo mouse infection

280 studies were performed at the University of Rochester in accordance with protocols approved by the

281 Institutional Animal Care and Use Committee at the University.

\section{$282 \quad$ Luminex-based cytokine measurements}

283 Serum IL-27 levels were determined in patients via Luminex assay using the Milliplex xMAP Multiplex 284 Assay (MilliporeSigma) according to the manufacturer's instructions. Primary bone marrow-derived 
murine macrophages (BMDMs) were pretreated with PBS or murine IL-27 (50 ng/ml from BioLegend) for 24 hours and then infected with $S$. aureus at MOI $=10$ in the presence or absence of murine IL-27 $(50 \mathrm{ng} / \mathrm{ml})$ for 24 hours. Subsequently, the cell culture supernatants were harvested from these cells to measure the following cytokines using a multiarray Milliplex xMAP murine cytokine Magnetic Bead Panel according to manufacturer's instructions: CD40L, GM-CSF, IFN- $\gamma$, IL-1 $\beta$, IL-2, IL-4, IL-5, IL-6,

IL-10, IL-13, IL-15, IL-17A, IL-17F, IL-21, IL-22, IL-23, IFN- 3 3/IL-28B, IL-31, IL-33, MIP-

$2913 \alpha /$ CCL20, TNF- $\alpha$, and TNF- $\beta$.

\section{In vitro IL-27 induction assay in macrophages}

293 Primary BMDMs from 12-week-old C57BL/6 mice (Jackson Laboratory) were isolated from femur and tibia. After dissection of the femur and tibia from mice, bones were washed in RPMI $+10 \%$ FBS, $1 \%$ HEPES, and 1\% anti-microbial/anti-mycotic (R10) media before disinfection using 70\% ethanol. After disinfection, the long bones were cut on both ends, and marrow was flushed using a 23G needle and resuspended in R10 media. After spinning cells down at 500g for ten minutes, the isolated cells were resuspended in a red lysis buffer to remove red blood cells. Cells were then resuspended again in R10 media with mouse colony-stimulating factor (M-CSF) $(25 \mathrm{ng} / \mathrm{mL})$ and plated at $5 \times 10^{6}$ cells $/$ plate for 6 days. Subsequently, BMDMs were differentiated with PBS, murine IFN- $\gamma$ (50 ng/ml from PeproTech) or murine IL-4 (20 ng/ml from PeproTech) in R10 for 24 hours to generate M0, M1, and M2 cells respectively [61]. These cells were then infected with $S$. aureus USA300 at MOI $=10$ for 24 hours, and

subsequently, the cell culture supernatant was harvested to examine IL-27 secretion using the Mouse IL-

27 Uncoated ELISA kit (Invitrogen).

$\underline{\text { Reactive nitrogen species induction in murine macrophages }}$

Murine BMDMs were pretreated with PBS or murine IL-27 (50 ng/ml from Biolegend) for 24 hours, 
310 pretreatment. Subsequently, nitrite concentrations in cell culture supernatant were determined via Griess

311 reaction assay kit (R\&D Systems).

312 Transwell Chemotaxis assay

313 HL-60 cells (ATCC) were differentiated into granulocytes using 100mM dimethylformamide (DMF)

314 (MilliporeSigma), placed on top of Boyden chambers, and chemotaxis assay was performed according

315 to manufacturer's protocol (MilliporeSigma $\mathrm{QCM}^{\mathrm{TM}}$ Chemotaxis $5 \mu \mathrm{m}$ 24-Well Cell Migration Assay

316 kit). Briefly, $1 \times 10^{6}$ cells/chamber were subjected to chemotaxis in RPMI media with or without the

317 chemoattractant (human IL-27 (500 ng/ml from PeproTech) or N-formyl-methionyl-leucyl-

318 phenylalanine (fMLP) (800 ng/mL from MilliporeSigma) as positive control)) placed below the

319 chamber, and incubated for 1 hour at $37^{\circ} \mathrm{C}$. Post incubation, cell migration from the chambers was

320 enumerated as relative fluorescence units (RFUs) according to the manufacturer's instructions.

321 Recombinant IL-27-expressing adeno-associated virus vector (rAAV-IL-27) administration

322 To get sustained exogenous IL-27 expression, mice were subjected to intramuscular administration of

323 recombinant murine IL-27-expressing AAV $\left(0.5 \times 10^{12}\right.$ genome copies/mouse, Vector Biolabs $) 7$ days

324 prior to $S$. aureus septic surgery [64]. Mice intramuscularly infected with AAV expressing recombinant

325 GFP $\left(0.5 \times 10^{12}\right.$ genome copies/ mouse, Vector Biolabs $)$ were used as controls.

326 Implant-associated MRSA osteomyelitis in mice

$327 \mathrm{C} 57 \mathrm{BL} / 6$ and IL-27R $\alpha$ deficient mice (IL-27R $\alpha^{-/}$) in the C57BL/6 background used in the study were

328 purchased from Jackson Laboratories and maintained at the University of Rochester animal facilities.

329 All in vivo $S$. aureus challenge experiments in mice utilized our well-validated transtibial implant-

330 associated osteomyelitis model [32-34, 36, 59]. Briefly, L-shaped stainless-steel implant was

331 contaminated with USA300 LAC $\left(5.0 \times 10^{5} \mathrm{CFU} / \mathrm{mL}\right)$ grown overnight, and surgically implanted into

332 the tibia of 8-week-old female C57BL/6 mice from the medial to the lateral side. Longitudinal body

333 weight change and bioluminescent intensity at infection site were evaluated, and terminal assessment of

334 CFU (implant, surgical site soft tissue and tibia), peri-implant osteolysis (high-resolution $\mu \mathrm{CT}$ imaging), 
bioRxiv preprint doi: https://doi.org/10.1101/2021.05.20.444931; this version posted May 20, 2021. The copyright holder for this preprint (which was not certified by peer review) is the author/funder, who has granted bioRxiv a license to display the preprint in perpetuity. It is made available under aCC-BY 4.0 International license.

335 biofilm formation on the implant (Zeiss Auriga SEM imaging), and histopathology were performed on

336 day 14 post-septic surgery as described previously [32-34, 36, 59]. Murine infection studies were

337 performed three independent times, and the resulting data was pooled from these experiments.

$338 \quad$ RNA sequencing of MRSA infected tibia

339 C57BL/6 were intramuscularly injected with rAAV-IL-27 or rAAV-GFP and then challenged with an $S$. 340 aureus contaminated transtibial implant as described above. Infected tibiae were collected on days 1, 3, 3417 , and 14 post-surgery for RNA sequencing. Tibiae were pulverized in liquid nitrogen $\left(-196{ }^{\circ} \mathrm{C}\right)$ and 342 homogenized using Bullet Blender Gold (Next Advance). Collection of Total RNA from homogenized 343 tibia was performed using TRIzol extraction (ThermoFisherScientific) and RNeasy Mini Kits (Qiagen). 344 Contaminating genomic DNA was removed using TURBO DNase (ThermoFisherScientific). The 345 TruSeq Stranded Total RNA Library Prep Gold (Illumina) was utilized for next-generation sequencing 346 library preparation per the manufacturer's instructions. The libraries were sequenced with the Illumina 347 NovaSeq6000 platform (Illumina). Quality filtering and adapter removal were performed by fastp 348 version 0.20 .0 [65] using the following parameters: “--in1 ../\$(SAMPLE)_R1.fastq.gz --out1 349 clt_\$(SAMPLE)_R1.fastq.gz --length_required 35 --cut_front_window_size 1 --cut_front_mean_quality 35013 --cut_front --cut_tail_window_size 1 --cut_tail_mean_quality 13 --cut_tail -w 8 -y -r -j 351 \$(SAMPLE)_fastp.json”. The remaining high quality processed reads were then mapped to the $M u s$ 352 musculus genome reference (GRCm38.p6) with STAR version 2.7.0f [66] using the following 353 parameters: “--twopassMode Basic --runMode alignReads --genomeDir \$(GENOME) --readFilesIn 354 \$(SAMPLE) --outSAMtype BAM Unsorted --outSAMstrandField intronMotif --outFilterIntronMotifs 355 RemoveNoncanonical". The mapped reads were counted within the GRCm38.p6 gene annotations using 356 the featureCounts read quantification program in Subread version 1.6.4 [67]. Then, the differential 357 expression analyses and data normalization were performed using DESeq2 version 1.22.1 [68] within 358 the $\mathrm{R}$ version 3.5.1 with a p-value threshold of 0.05 on each set of raw expression measure. Subsequent 359 bioinformatics analyses including Canonical Pathway Analysis and Regulator Effect Network Analysis 
bioRxiv preprint doi: https://doi.org/10.1101/2021.05.20.444931; this version posted May 20, 2021. The copyright holder for this preprint (which

was not certified by peer review) is the author/funder, who has granted bioRxiv a license to display the preprint in perpetuity. It is made available under aCC-BY 4.0 International license.

360 were performed using Ingenuity Pathway Analysis (IPA; Qiagen) for each time-point. All generated

361 sequence data have been submitted to Gene Expression Omnibus with accession number GSE168896.

$362 \underline{\text { Statistics }}$

363 For statistical analyses, the non-parametric Kruskal-Wallis test, one-way ANOVA, repeated measures

364 two-way ANOVA, and unpaired student's t-test were utilized to assess significance between

365 experimental groups. Data were presented as mean \pm standard deviation. A $p$ value less than 0.05 was

366 considered significant. 
bioRxiv preprint doi: https://doi.org/10.1101/2021.05.20.444931; this version posted May 20, 2021. The copyright holder for this preprint (which

was not certified by peer review) is the author/funder, who has granted bioRxiv a license to display the preprint in perpetuity. It is made available under aCC-BY 4.0 International license.

\section{Acknowledgments}

368 The authors would also like to thank Drs. Chad Galloway and Elysia A. Masters for their technical

369 assistance. The authors would like to thank the Electron Microscope Shared Resource Laboratory,

370 Genomics Research Center, and the Histology, Biochemistry, and Molecular Imaging Core in the Center

371 for Musculoskeletal Research at the University of Rochester Medical Center.

\section{Funding}

374 This work was supported by NIH NIAMS P30 AR069655 pilot grant (GM) with additional support from 375 NIH NIAMS P50 AR072000 (EMS), P30 AR069655 (EMS), and AO Trauma Clinical Priority Program 376 (EMS, SLK).

\section{Conflict of interest statement}

379 The authors have declared that no conflict of interest exists.

380

\section{Data availability}

382 All RNA sequence data have been submitted to the Gene Expression Omnibus with accession number 383 GSE168896. 


\section{References}

1. Schwarz EM, Parvizi J, Gehrke T, Aiyer A, Battenberg A, Brown SA, et al. 2018 International Consensus Meeting on Musculoskeletal Infection: Research Priorities from the General Assembly Questions. J Orthop Res. 2019;37(5):997-1006. Epub 2019/04/13. doi: 10.1002/jor.24293. PubMed PMID: 30977537.

2. Tande AJ, Patel R. Prosthetic joint infection. Clin Microbiol Rev. 2014;27(2):302-45. Epub 2014/04/04. doi: 10.1128/CMR.00111-13. PubMed PMID: 24696437; PubMed Central PMCID: PMCPMC3993098.

3. Stulberg JJ, Delaney CP, Neuhauser DV, Aron DC, Fu P, Koroukian SM. Adherence to surgical care improvement project measures and the association with postoperative infections. Jama. 2010;303(24):2479-85. Epub 2010/06/24. doi: 10.1001/jama.2010.841. PubMed PMID: 20571014. 4. Kates SL, Tornetta P, 3rd. Commentary on Secondary Fracture Prevention: Consensus Clinical Recommendations From a Multistakeholder Coalition Originally Published in the Journal of Bone and Mineral Research. J Orthop Trauma. 2020;34(4):221. Epub 2020/03/21. doi: 10.1097/BOT.0000000000001742. PubMed PMID: 32195890.

5. Goodson KM, Kee JR, Edwards PK, Novack AJ, Stambough JB, Siegel ER, et al. Streamlining Hospital Treatment of Prosthetic Joint Infection. J Arthroplasty. 2020;35(3S):S63-S8. Epub 2020/02/13. doi: 10.1016/j.arth.2019.10.056. PubMed PMID: 32046835.

6. Depypere M, Morgenstern M, Kuehl R, Senneville E, Moriarty TF, Obremskey WT, et al. Pathogenesis and management of fracture-related infection. Clin Microbiol Infect. 2020;26(5):572-8. Epub 2019/08/26. doi: 10.1016/j.cmi.2019.08.006. PubMed PMID: 31446152.

7. Govaert GAM, Kuehl R, Atkins BL, Trampuz A, Morgenstern M, Obremskey WT, et al. Diagnosing Fracture-Related Infection: Current Concepts and Recommendations. J Orthop Trauma. 2020;34(1):8-17. Epub 2019/12/20. doi: 10.1097/BOT.0000000000001614. PubMed PMID: 31855973; PubMed Central PMCID: PMCPMC6903359.

8. Kandel CE, Jenkinson R, Daneman N, Backstein D, Hansen BE, Muller MP, et al. Predictors of Treatment Failure for Hip and Knee Prosthetic Joint Infections in the Setting of 1- and 2-Stage Exchange Arthroplasty: A Multicenter Retrospective Cohort. Open Forum Infect Dis. 2019;6(11):ofz452. Epub 2019/11/19. doi: 10.1093/ofid/ofz452. PubMed PMID: 31737739; PubMed Central PMCID: PMCPMC6847009.

9. Masters EA, Trombetta RP, de Mesy Bentley KL, Boyce BF, Gill AL, Gill SR, et al. Evolving concepts in bone infection: redefining "biofilm", "acute vs. chronic osteomyelitis", "the immune proteome" and "local antibiotic therapy". Bone Res. 2019;7:20. doi: 10.1038/s41413-019-0061-z. PubMed PMID: 31646012; PubMed Central PMCID: PMCPMC6804538.

10. Kaplan SL. Recent lessons for the management of bone and joint infections. J Infect. 2014;68 Suppl 1:S51-6. Epub 2013/10/15. doi: 10.1016/j.jinf.2013.09.014. PubMed PMID: 24119927. 11. Assis LM, Nedeljkovic M, Dessen A. New strategies for targeting and treatment of multi-drug resistant Staphylococcus aureus. Drug Resist Updat. 2017;31:1-14. Epub 2017/09/05. doi: 10.1016/j.drup.2017.03.001. PubMed PMID: 28867240.

12. Weigelt JA, Lipsky BA, Tabak YP, Derby KG, Kim M, Gupta V. Surgical site infections: Causative pathogens and associated outcomes. Am J Infect Control. 2010;38(2):112-20. Epub 2009/11/06. doi: 10.1016/j.ajic.2009.06.010. PubMed PMID: 19889474.

13. van Hal SJ, Jensen SO, Vaska VL, Espedido BA, Paterson DL, Gosbell IB. Predictors of mortality in Staphylococcus aureus Bacteremia. Clinical microbiology reviews. 2012;25(2):362-86. Epub 2012/04/12. doi: 10.1128/CMR.05022-11. PubMed PMID: 22491776; PubMed Central PMCID: PMCPMC3346297. 
430 14. Wong HR, Lindsell CJ, Lahni P, Hart KW, Gibot S. Interleukin 27 as a sepsis diagnostic biomarker in critically ill adults. Shock. 2013;40(5):382-6. doi: 10.1097/SHK.0b013e3182a67632. PubMed PMID: 23903853; PubMed Central PMCID: PMCPMC3800476. 15. Wong HR, Liu KD, Kangelaris KN, Lahni P, Calfee CS. Performance of interleukin-27 as a sepsis diagnostic biomarker in critically ill adults. J Crit Care. 2014;29(5):718-22. doi: 10.1016/j.jcrc.2014.04.004. PubMed PMID: 24848949; PubMed Central PMCID: PMCPMC4141017. 16. Hanna WJ, Berrens Z, Langner T, Lahni P, Wong HR. Interleukin-27: a novel biomarker in predicting bacterial infection among the critically ill. Crit Care. 2015;19:378. doi: 10.1186/s13054-0151095-2. PubMed PMID: 26514771; PubMed Central PMCID: PMCPMC4627377.

17. He Y, Du WX, Jiang HY, Ai Q, Feng J, Liu Z, et al. Multiplex Cytokine Profiling Identifies Interleukin-27 as a Novel Biomarker For Neonatal Early Onset Sepsis. Shock. 2017;47(2):140-7. doi: 10.1097/SHK.0000000000000753. PubMed PMID: 27648693. 18. Jacobs L, Berrens Z, Stenson EK, Zackoff M, Danziger-Isakov L, Lahni P, et al. Interleukin-27 as a candidate diagnostic biomarker for bacterial infection in immunocompromised pediatric patients. PLoS One. 2018;13(11):e0207620. doi: 10.1371/journal.pone.0207620. PubMed PMID: 30475852; PubMed Central PMCID: PMCPMC6261028. 19. Wong HR CN, Hall M, Allen GL, Thomas NJ, Freishtat RJ, Anas N, Meyer K, Checchia PA, Lin R, Bigham MT, Sen A, Nowak J, Quasney M, Henricksen JW, Chopra A, Banschbach S, Beckman E, Harmon K, Lahni P, Shanley TP. Interleukin-27 is a novel candidate diagnostic biomarker for bacterial infection in critically ill children. Crit Care. 2012;16(5): R213. doi: 10.1186/cc11847.

20. Yoshida H, Hunter CA. The immunobiology of interleukin-27. Annu Rev Immunol. 2015;33:417-43. Epub 2015/04/12. doi: 10.1146/annurev-immunol-032414-112134. PubMed PMID: 25861977.

21. Hunter CA. New IL-12-family members: IL-23 and IL-27, cytokines with divergent functions. Nature reviews Immunology. 2005;5(7):521-31. Epub 2005/07/07. doi: 10.1038/nri1648. PubMed PMID: 15999093.

22. Pflanz S TJ, Cheung J, Rosales R, Kanzler H, Gilbert J, Hibbert L, Churakova T TM, Vaisberg E, Blumenschein WM, Mattson JD, Wagner JL, To W, , Zurawski S MT, Gorman DM, Bazan JF, de Waal Malefyt R, Rennick D, RA. K. IL-27, a heterodimeric cytokine composed of EBI3 and p28 protein, induces proliferation of naive CD4+ T cells. Immunity. 2002;16(6):779-90. doi: 10.1016/s10747613(02)00324-2

461 23. Morita YM, E.A.; Schwarz, E.M.; Muthukrishnan G. Interleukin-27 and its diverse effects on bacterial infections. Frontiers in Immunology. 2021;(In press).

24. Diveu C, McGeachy MJ, Boniface K, Stumhofer JS, Sathe M, Joyce-Shaikh B, et al. IL-27 blocks RORc expression to inhibit lineage commitment of Th17 cells. J Immunol. 2009; 182(9):5748-56. Epub 2009/04/22. doi: 10.4049/jimmunol.0801162. PubMed PMID: 19380822.

25. Hall AO, Beiting DP, Tato C, John B, Oldenhove G, Lombana CG, et al. The cytokines interleukin 27 and interferon-gamma promote distinct Treg cell populations required to limit infectioninduced pathology. Immunity. 2012;37(3):511-23. Epub 2012/09/18. doi:

10.1016/j.immuni.2012.06.014. PubMed PMID: 22981537; PubMed Central PMCID: PMCPMC3477519.

26. Cao J, Xu F, Lin S, Song Z, Zhang L, Luo P, et al. IL-27 controls sepsis-induced impairment of lung antibacterial host defence. Thorax. 2014;69(10):926-37. Epub 2014/07/31. doi: 10.1136/thoraxjnl2014-205777. PubMed PMID: 25074706.

27. Robinson KM, Lee B, Scheller EV, Mandalapu S, Enelow RI, Kolls JK, et al. The role of IL-27 in susceptibility to post-influenza Staphylococcus aureus pneumonia. Respir Res. 2015;16:10. Epub 2015/02/06. doi: 10.1186/s12931-015-0168-8. PubMed PMID: 25651926; PubMed Central PMCID: PMCPMC4324414. 
28. Seita J, Asakawa M, Ooehara J, Takayanagi S, Morita Y, Watanabe N, et al. Interleukin-27 directly induces differentiation in hematopoietic stem cells. Blood. 2008;111(4):1903-12. doi: 10.1182/blood-2007-06-093328. PubMed PMID: 18042804.

29. Pflanz S, Hibbert L, Mattson J, Rosales R, Vaisberg E, Bazan JF, et al. WSX-1 and glycoprotein 130 constitute a signal-transducing receptor for IL-27. J Immunol. 2004;172(4):2225-31. doi: 10.4049/jimmunol.172.4.2225. PubMed PMID: 14764690.

30. Guzzo C, Che Mat NF, Gee K. Interleukin-27 induces a STAT1/3- and NF-kappaB-dependent proinflammatory cytokine profile in human monocytes. J Biol Chem. 2010;285(32):24404-11. doi: 10.1074/jbc.M1 10.112599. PubMed PMID: 20519510; PubMed Central PMCID: PMCPMC2915676. 31. Lucas S, Ghilardi N, Li J, de Sauvage FJ. IL-27 regulates IL-12 responsiveness of naive CD4+ T cells through Stat1-dependent and -independent mechanisms. Proc Natl Acad Sci U S A. 2003;100(25):15047-52. doi: 10.1073/pnas.2536517100. PubMed PMID: 14657353; PubMed Central PMCID: PMCPMC299900.

32. Nishitani K, Sutipornpalangkul W, de Mesy Bentley KL, Varrone JJ, Bello-Irizarry SN, Ito H, et al. Quantifying the natural history of biofilm formation in vivo during the establishment of chronic implant-associated Staphylococcus aureus osteomyelitis in mice to identify critical pathogen and host factors. J Orthop Res. 2015;33(9):1311-9. doi: 10.1002/jor.22907. PubMed PMID: 25820925; PubMed Central PMCID: PMCPMC4529770.

33. Masters EA, de Mesy Bentley KL, Gill AL, Hao SP, Galloway CA, Salminen AT, et al. Identification of Penicillin Binding Protein 4 (PBP4) as a critical factor for Staphylococcus aureus bone invasion during osteomyelitis in mice. PLoS Pathog. 2020;16(10):e1008988. doi: 10.1371/journal.ppat.1008988. PubMed PMID: 33091079; PubMed Central PMCID: PMCPMC7608983 silicon-based technologies.

34. Nishitani K, Ishikawa M, Morita Y, Yokogawa N, Xie C, de Mesy Bentley KL, et al. IsdB antibody-mediated sepsis following S. aureus surgical site infection. JCI Insight. 2020;5(19). doi: 10.1172/jci.insight.141164. PubMed PMID: 33004694; PubMed Central PMCID: PMCPMC7566716. 35. Masters EA, Hao SP, Kenney HM, Morita Y, Galloway CA, de Mesy Bentley KL, et al. Distinct vasculotropic versus osteotropic features of S. agalactiae versus S. aureus implant-associated bone infection in mice. J Orthop Res. 2021;39(2):389-401. doi: 10.1002/jor.24962. PubMed PMID: 33336806.

36. Varrone JJ, de Mesy Bentley KL, Bello-Irizarry SN, Nishitani K, Mack S, Hunter JG, et al. Passive immunization with anti-glucosaminidase monoclonal antibodies protects mice from implantassociated osteomyelitis by mediating opsonophagocytosis of Staphylococcus aureus megaclusters. J Orthop Res. 2014;32(10):1389-96. doi: 10.1002/jor.22672. PubMed PMID: 24992290; PubMed Central PMCID: PMCPMC4234088.

37. Frangieh M, McHenry A, Phillips R, Ye C, Bernier A, Laffel L, et al. IL-27: An endogenous constitutive repressor of human monocytes. Clin Immunol. 2020;217:108498. doi:

10.1016/j.clim.2020.108498. PubMed PMID: 32531345.

38. Ivanov, II, McKenzie BS, Zhou L, Tadokoro CE, Lepelley A, Lafaille JJ, et al. The orphan nuclear receptor RORgammat directs the differentiation program of proinflammatory IL-17+ T helper cells. Cell. 2006;126(6):1121-33. doi: 10.1016/j.cell.2006.07.035. PubMed PMID: 16990136. 39. Fan J, Zhang YC, Zheng DF, Zhang M, Liu H, He M, et al. IL-27 is elevated in sepsis with acute hepatic injury and promotes hepatic damage and inflammation in the CLP model. Cytokine. 2020;127:154936. doi: 10.1016/j.cyto.2019.154936. PubMed PMID: 31786500.

40. Muthukrishnan G, Masters EA, Daiss JL, Schwarz EM. Mechanisms of Immune Evasion and Bone Tissue Colonization That Make Staphylococcus aureus the Primary Pathogen in Osteomyelitis. Curr Osteoporos Rep. 2019. Epub 2019/11/14. doi: 10.1007/s11914-019-00548-4. PubMed PMID: 31721069. 
41. Wang L, Cao J, Li C, Zhang L. IL-27/IL-27 Receptor Signaling Provides Protection in Clostridium difficile-Induced Colitis. J Infect Dis. 2018;217(2):198-207. doi: 10.1093/infdis/jix581. PubMed PMID: 29140433.

42. Gao F, Yang YZ, Feng XY, Fan TT, Jiang L, Guo R, et al. Interleukin-27 is elevated in sepsisinduced myocardial dysfunction and mediates inflammation. Cytokine. 2016;88:1-11. doi: 10.1016/j.cyto.2016.08.006. PubMed PMID: 27525353.

43. Lin Y, Su J, Wang Y, Xu D, Zhang X, Yu B. mRNA transcriptome analysis of bone in a mouse model of implant-associated Staphylococcus aureus osteomyelitis. Infect Immun. 2021. doi: 10.1128/IAI.00814-20. PubMed PMID: 33619031.

44. Milner JD, Brenchley JM, Laurence A, Freeman AF, Hill BJ, Elias KM, et al. Impaired T(H)17 cell differentiation in subjects with autosomal dominant hyper-IgE syndrome. Nature. 2008;452(7188):773-6. doi: 10.1038/nature06764. PubMed PMID: 18337720; PubMed Central PMCID: PMCPMC2864108.

45. Marques JM, Rial A, Munoz N, Pellay FX, Van Maele L, Leger H, et al. Protection against Streptococcus pneumoniae serotype 1 acute infection shows a signature of Th17- and IFN-gammamediated immunity. Immunobiology. 2012;217(4):420-9. doi: 10.1016/j.imbio.2011.10.012. PubMed PMID: 22204818.

46. Lubberts E KM, van den Berg WB. The role of T-cell interleukin-17 in conducting destructive arthritis: lessons from animal models. Arthritis Res Ther. 2005;7(1):29-37. doi: 10.1186/ar1478).

47. Eastaff-Leung N, Mabarrack N, Barbour A, Cummins A, Barry S. Foxp3+ regulatory T cells, Th17 effector cells, and cytokine environment in inflammatory bowel disease. J Clin Immunol. 2010;30(1):80-9. doi: 10.1007/s10875-009-9345-1. PubMed PMID: 19936899.

48. Roeleveld DM, Koenders MI. The role of the Th17 cytokines IL-17 and IL-22 in Rheumatoid Arthritis pathogenesis and developments in cytokine immunotherapy. Cytokine. 2015;74(1):101-7. doi: 10.1016/j.cyto.2014.10.006. PubMed PMID: 25466295.

49. Kamiya S, Nakamura C, Fukawa T, Ono K, Ohwaki T, Yoshimoto T, et al. Effects of IL-23 and IL-27 on osteoblasts and osteoclasts: inhibitory effects on osteoclast differentiation. J Bone Miner Metab. 2007;25(5):277-85. doi: 10.1007/s00774-007-0766-8. PubMed PMID: 17704992.

50. Shukla P, Mansoori MN, Kakaji M, Shukla M, Gupta SK, Singh D. Interleukin 27 (IL-27) Alleviates Bone Loss in Estrogen-deficient Conditions by Induction of Early Growth Response-2 Gene. J Biol Chem. 2017;292(11):4686-99. doi: 10.1074/jbc.M116.764779. PubMed PMID: 28130449; PubMed Central PMCID: PMCPMC5377783.

51. Li X LW, Hu J, Chen Y, Yu T, Yang J, Dong S, Tian X, Sun L. Interleukin-27 prevents LPSinduced inflammatory osteolysis by inhibiting osteoclast formation and function. Am J Transl Res. 2019;11(3):1154-1169.; PubMed Central PMCID: PMCPMC6456512.

52. Terkawi MA, Kadoya K, Takahashi D, Tian Y, Hamasaki M, Matsumae G, et al. Identification of IL-27 as potent regulator of inflammatory osteolysis associated with vitamin E-blended ultra-high molecular weight polyethylene debris of orthopedic implants. Acta Biomater. 2019;89:242-51. doi: 10.1016/j.actbio.2019.03.028. PubMed PMID: 30880234.

53. Holscher C, Holscher A, Ruckerl D, Yoshimoto T, Yoshida H, Mak T, et al. The IL-27 receptor chain WSX-1 differentially regulates antibacterial immunity and survival during experimental tuberculosis. J Immunol. 2005;174(6):3534-44. doi: 10.4049/jimmunol.174.6.3534. PubMed PMID: 15749890.

54. Owaki T, Asakawa M, Kamiya S, Takeda K, Fukai F, Mizuguchi J, et al. IL-27 suppresses CD28-mediated [correction of medicated] IL-2 production through suppressor of cytokine signaling 3. J Immunol. 2006;176(5):2773-80. doi: 10.4049/jimmunol.176.5.2773. PubMed PMID: 16493033. 55. Karakhanova S, Bedke T, Enk AH, Mahnke K. IL-27 renders DC immunosuppressive by induction of B7-H1. J Leukoc Biol. 2011;89(6):837-45. doi: 10.1189/jlb.1209788. PubMed PMID: 21345970. 
56. Schneider R, Yaneva T, Beauseigle D, El-Khoury L, Arbour N. IL-27 increases the proliferation and effector functions of human naive CD8+ T lymphocytes and promotes their development into Tc1 cells. Eur J Immunol. 2011;41(1):47-59. doi: 10.1002/eji.201040804. PubMed PMID: 21182076. 57. Petes C, Odoardi N, Plater SM, Martin NL, Gee K. IL-27 amplifies cytokine responses to Gramnegative bacterial products and Salmonella typhimurium infection. Sci Rep. 2018;8(1):13704. doi: 10.1038/s41598-018-32007-y. PubMed PMID: 30209294; PubMed Central PMCID: PMCPMC6135775.

58. Choi YH, Lim EJ, Kim SW, Moon YW, Park KS, An HJ. IL-27 enhances IL-15/IL-18-mediated activation of human natural killer cells. J Immunother Cancer. 2019;7(1):168. doi: 10.1186/s40425-0190652-7. PubMed PMID: 31277710; PubMed Central PMCID: PMCPMC6612093.

59. Muthukrishnan G, Wallimann A, Rangel-Moreno J, Bentley KLdM, Hildebrand M, Mys K, et al. Humanized Mice Exhibit Exacerbated Abscess Formation and Osteolysis During the Establishment of Implant-Associated Staphylococcus aureus Osteomyelitis. Frontiers in Immunology. 2021;12(809). doi: 10.3389/fimmu.2021.651515.

60. Morgenstern M, Erichsen C, Militz M, Xie Z, Peng J, Stannard J, et al. The AO trauma CPP bone infection registry: Epidemiology and outcomes of Staphylococcus aureus bone infection. J Orthop Res. 2020. Epub 2020/07/29. doi: 10.1002/jor.24804. PubMed PMID: 32720352.

61. Murray PJ AJ, Biswas SK, Fisher EA, Gilroy DW, Goerdt S, Gordon S, Hamilton JA, Ivashkiv LB, Lawrence T, Locati M, Mantovani A, Martinez FO, Mege JL, Mosser DM, Natoli G, Saeij JP, Schultze JL, Shirey KA, Sica A, Suttles J, Udalova I, van Ginderachter JA, Vogel SN, Wynn TA. Macrophage activation and polarization: nomenclature and experimental guidelines. Immunity. 2014;41(1):14-20. doi: doi: 10.1016/j.immuni.2014.06.008.

62. Lu SC, Wu HW, Lin YJ, Chang SF. The essential role of Oct-2 in LPS-induced expression of iNOS in RAW 264.7 macrophages and its regulation by trichostatin A. Am J Physiol Cell Physiol. 2009;296(5):C1133-9. doi: 10.1152/ajpcell.00031.2009. PubMed PMID: 19279235.

63. Fang FC, Vazquez-Torres A. Reactive nitrogen species in host-bacterial interactions. Curr Opin Immunol. 2019;60:96-102. doi: 10.1016/j.coi.2019.05.008. PubMed PMID: 31200187; PubMed Central PMCID: PMCPMC6800629.

64. Zhu X, Liu Z, Liu JQ, Zhu J, Zhang J, Davis JP, et al. Systemic delivery of IL-27 by an adenoassociated viral vector inhibits $\mathrm{T}$ cell-mediated colitis and induces multiple inhibitory pathways in $\mathrm{T}$ cells. J Leukoc Biol. 2016;100(2):403-11. Epub 2016/04/24. doi: 10.1189/j1b.3A1215-540R. PubMed PMID: 27106672; PubMed Central PMCID: PMCPMC4945352.

65. Chen S, Zhou Y, Chen Y, Gu J. fastp: an ultra-fast all-in-one FASTQ preprocessor.

Bioinformatics. 2018;34(17):i884-i90. doi: 10.1093/bioinformatics/bty560. PubMed PMID: 30423086; PubMed Central PMCID: PMCPMC6129281.

66. Dobin A, Davis CA, Schlesinger F, Drenkow J, Zaleski C, Jha S, et al. STAR: ultrafast universal RNA-seq aligner. Bioinformatics. 2013;29(1):15-21. doi: 10.1093/bioinformatics/bts635. PubMed PMID: 23104886; PubMed Central PMCID: PMCPMC3530905.

67. Liao Y, Smyth GK, Shi W. The Subread aligner: fast, accurate and scalable read mapping by seed-and-vote. Nucleic Acids Res. 2013;41(10):e108. doi: 10.1093/nar/gkt214. PubMed PMID: 23558742; PubMed Central PMCID: PMCPMC3664803.

68. Love MI, Huber W, Anders S. Moderated estimation of fold change and dispersion for RNA-seq data with DESeq2. Genome Biol. 2014;15(12):550. doi: 10.1186/s13059-014-0550-8. PubMed PMID: 25516281; PubMed Central PMCID: PMCPMC4302049. 
620 Table 1. In vitro cytokine assay with $S$. aureus infected murine bone marrow derived macrophages

621 in the presence or absence of IL-27

PBS+S.aureus infection

\begin{tabular}{l}
\hline IL-1 $\beta$ \\
IL-2 \\
IL-4 \\
IL-5 \\
IL-6 \\
IL-10 \\
IL-13 \\
IL-15 \\
IL-17A \\
IL-17F \\
IL-21 \\
IL-22 \\
IL-23 \\
IL-31 \\
IL-33
\end{tabular}

IFN-Y

IFN- $\lambda 3 / I L-28 B$

TNF- $\alpha$

TNF- $\beta$

GM-CSF

MIP-3a/CCL20

CD40L
$99.1 \pm 28.7$

$144.9 \pm 2.2$

$168.0 \pm 3.3$

$518.8 \pm 9.9$

$12595.4 \pm 1263.0$

$3721.7 \pm 27.0$

$1354.3 \pm 28.2$

$41387.8 \pm 1327.2$

$747.3 \pm 60.4$

$1079.8 \pm 19.1$

$2279.2 \pm 91.6$

$1827.6 \pm 61.4$

$7492.5 \pm 182.3$

$2454.4 \pm 94.1$

$10965.5 \pm 125.8$

$164.3 \pm 3.5$

$472.9 \pm 13.8$

$500.2 \pm 24.4$

$87365.0 \pm 1032.4$

$265.0 \pm 11.1$

$5648.3 \pm 247.4$

$9229.2 \pm 87.6$
IL-27+S.aureus infection

$90.8 \pm 14.4$

$155.2 \pm 8.7$

$174.5 \pm 7.9$

$554.4 \pm 31.2$

$10174.4 \pm 2138.8$

$3915.8 \pm 129.7^{*}$

$1397.1 \pm 141.8$

$42200.2 \pm 2124.3$

$778.3 \pm 61.0$

$1099.1 \pm 64.1$

$2439.9 \pm 20.0 *$

$1859.3 \pm 84.1$

$8042.7 \pm 142.0$

$2672.7 \pm 25.3 * *$

$11595.4 \pm 701.2$

$167.5 \pm 8.8$

$488.4 \pm 37.1$

$482.7 \pm 9.5$

$99471.3 \pm 5440.6 * *$

$281.4 \pm 6.9$

$5670.9 \pm 37.3$

$9870.0 \pm 487.6$

623 Data are presented mean $+/-\mathrm{SD}(\mathrm{pg} / \mathrm{mL})\left(\mathrm{N}=3,{ }^{*} \mathrm{p}<0.05, * * \mathrm{p}<0.01\right.$, one-way ANOVA) 


\section{Figure Legends}

Figure 1. IL-27 levels are elevated in patients and in mice with S. aureus infection. A) Serum

samples were collected from healthy people $(\mathrm{n}=10)$, orthopaedic patients with culture confirmed $S$.

aureus bone infections $(\mathrm{n}=23)$, and patients who died from septic $S$. aureus osteomyelitis $(\mathrm{n}=5)$. Serum

IL-27 levels were determined via Luminex assay, and the data for each sample is presented with the

mean +/- SEM for the group. B) The Luminex data were utilized to perform a receiver operating

characteristic (ROC) curve, and the area under the curve (AUC) between controls and infected patients

631 is presented. Note that serum IL-27 levels are highly diagnostic of S. aureus osteomyelitis. The dashed

632 line represents a non-discriminatory test with equal sensitivity and specificity. In vitro cultures of $(\mathbf{C})$

633 RAW264.7 cells and (D) primary murine bone marrow-derived macrophages were differentiated with

634 PBS, IFN- $\gamma(50 \mathrm{ng} / \mathrm{ml})$ or IL-4 (20ng/ml) to generate M0, M1 and M2 cells respectively, and then

635 exposed to $S$. aureus USA300 (MOI = 10). These cultures were incubated for 24 hours, and IL-27 levels

636 in the supernatants were assessed via ELISA. The data from each experiment are presented with the

637 mean $+/-\mathrm{SD}$ for the group $(\mathrm{n}=3)(* p<0.05, * * p<0.01, * * * p<0.001 * * * * p<0.0001$, ANOVA).

Figure 2. Systemic IL-27 ameliorates surgical site soft tissue infection and osteolysis during $S$.

aureus implant-associated osteomyelitis. (A) 8-week-old female C57BL/6 mice received $0.5 \times 10^{12}$ genome copies/mouse of rAAV-IL-27 ( $=3$ ) or rAAV-GFP (control, $n=5)$ via intramuscular injection,

643 levels in sera are presented as the mean +/- SD. (B-F) A separate cohort of these mice were

644 intramuscularly injected with rAAV-IL-27 or rAAV-GFP $(\mathrm{n}=16)$, and then challenged 7 days later with

$6455 \times 10^{5}$ CFU of USA300 LAC::1ux on a contaminated transtibial pin as described in Materials and

646 Methods. Longitudinal BLI (B) and animal weight (C) were obtained on days 0, 1, 3, 7, 10 \& 14, and

647 the data are presented as the mean $+/-\mathrm{SD}\left(*^{*} p<0.05\right.$ on Day $3, * * * p<0.001$ on Day 10 and 14 , two-way

648 ANOVA). (D) Photographs of the infected tibiae were obtained on day 14, and representative images of 
the large vs. small draining abscesses observed in the rAAV-GFP and rAAV-IL-27 treated mice

respectively are shown. The mice were euthanized on day 14, and the infected tibiae were harvested for

CFU and micro-CT analyses. (E) CFUs from the implant, soft tissue and tibia were determined, and the

rAAV-GFP vs. rAAV-IL-27 treated tibiae are shown with the volumetric bone loss in the infected tibiae.

Data are presented for each tibia with the mean $+/-\mathrm{SD}$ for the group $\left(\mathrm{n}=6,{ }^{*} p<0.05, \mathrm{t}\right.$ test).

Figure 3. Absence of systemic IL-27 effects on implant associated osteomyelitis in IL-27R ${ }^{-/-}$mice. $^{-}$ from each tibia are presented with the mean $+/-$ SD for the group $(n=5)$. No differences were observed differential gene expression between rAAV-IL-27 and rAAV-GFP treated mice were evaluated using 
674 effect. $(* * * * p<0.0001$ on days $1 \& 3, * * * p<0.001$ on days $7 \& 14)$. (D) Venn diagram analyses showing

675 the overlap of DEGs across days 1, 3, 7 and 14 post-septic surgery in in mice treated with rAAV-IL-27

676 vs. rAAV-GFP, respectively. (E) Ingenuity Pathway Analysis (IPA) was utilized to identify canonical pathways of DEGs between rAAV-IL-27 vs. rAAV-GFP treated mice over time. Significant association

$\left({ }^{*} p<0.05\right)$ were calculated based on the Fisher's right tailed exact test. The orange and blue colored bars indicate predicted pathway activation or predicted pathway suppression in mice treated with rAAV-IL-

27 vs. rAAV-GFP respectively (z-score). White bars indicate z-score at or very close to 0 . Some pro-

681 inflammatory/immune pathways including IL-17 signaling, Th17 activating pathway, IL-2 signaling were activated in mice treated with rAAV-IL-27 on day 1 following infection. On the other hand, these pathways and others (e.g.) were estimated to be suppressed at later time points. Moreover, immunosuppressive PD-1/PD-L1 signaling pathway was upregulated at later time points. These results indicate that IL-27 is a biphasic cytokine that activates pro-inflammatory/immune pathways early upon S. aureus infection, and then suppresses them late to prevent tissue damage and cytokine storm.

Figure 5. IL-27 up-regulated pro-inflammatory cytokines during the initiation of implantassociated $S$. aureus osteomyelitis and their down-regulation during chronic infection. DEGs in the downregulated on day-14. 
rAAV-GFP treated infected tibiae on days 3, 7 and 14. (B) To confirm the gene expression data, tibiae

700 from the mice described Figure 2 were processed for histology. Representative 2x images of tibia

701 sections stained for TRAP (red/purple) are shown (scale bars $=500 \mu \mathrm{m}$ ). (C) \% TRAP-stained area was quantified within the cortical bone regions, trabecular bone regions, and implant sites (red box), and the data are presented for each tibia with the mean $+/-\mathrm{SD}$ for the group $(\mathrm{n}=6, * * p<0.05, \mathrm{t}$ test).

Figure 7. Schematic model of IL-27 mediated immune homeostasis during S. aureus osteomyelitis.

Here, we propose a model of IL-27-mediated immune homeostasis during $S$. aureus osteomyelitis in which IL-27 promotes host immune reaction against $S$. aureus osteomyelitis by regulating its reported onset of $S$. aureus osteomyelitis, IL-27 promotes production of pro-inflammatory cytokines, leading to enhanced bacteria killing by macrophages and neutrophils. (B) In contrast, at later stages of S. aureus

711 osteomyelitis following acute reaction, IL-27 decreases production of pro-inflammatory cytokines and 712 osteoclastogenesis, which prevents cytokine storm and osteolysis.

Supplemental Figure 1. Systemic IL-27 does not affect biofilm formation on the implant during $S$. and imaging after euthanasia on day 14 post-op. No difference was detected in \%biofilm formation area on implant between rAAV-IL-27 and rAAV-GFP challenged mice $(n=6)$. 
724 placed in the well below the chamber and incubated for 1 hour. Subsequently, cells which migrated in

725 each well were stained with fluorescent dye and signal intensity was evaluated using a fluorescent plate

726 reader $(\mathrm{n}=2)$. No difference in chemotactic activity of granulocytes was observed between the

727 experimental groups.

728

729 Supplemental Figure 3. IL-27 enhances LPS-induced NO- production by macrophage cultures.

730 Primary bone marrow derived murine macrophages were pretreated with PBS or IL-27 (50 ng/ml) for 24

731 hours, and then stimulated with LPS (100 ng/ml) in the presence or absence of IL-27 (50 ng/ml) for 24

732 hours. Nitrite levels in the culture supernatant was determined via Griess reaction assay, and the data

733 from each experiment are presented with the mean $+/$ SD for the group $\left(\mathrm{n}=3,{ }^{*} p<0.05,{ }^{*} p<0.01\right.$, $734 * * * * p<0.0001$ by one-way ANOVA). 

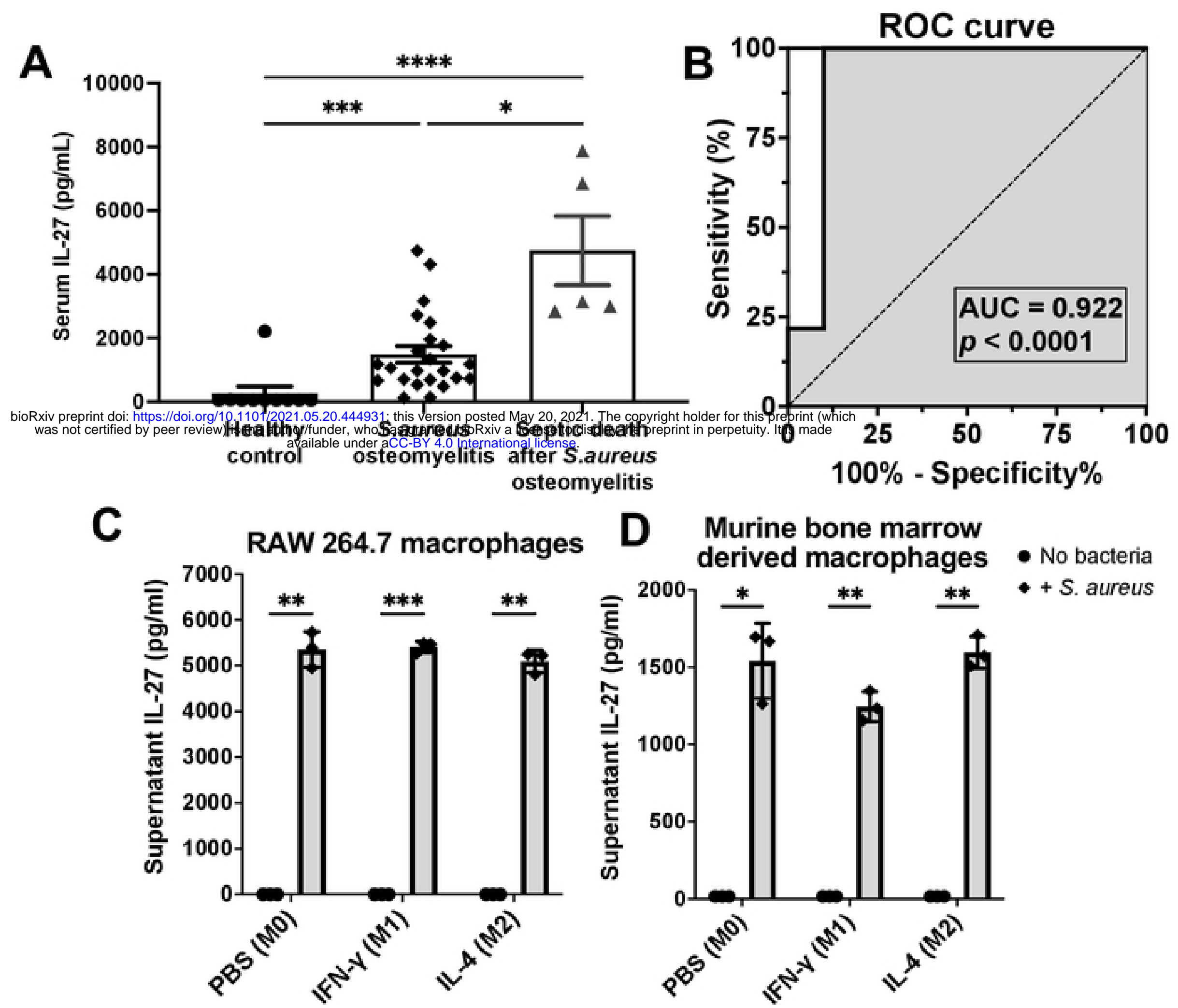

Figure 1. IL-27 levels are elevated in patients and in mice with $S$. aureus infection. A) Serum samples were collected from healthy people $(\mathrm{n}=10)$, orthopaedic patients with culture confirmed $S$. aureus bone infections $(\mathrm{n}=23)$, and patients who died from septic $S$. aureus osteomyelitis $(\mathrm{n}=5)$. Serum IL-27 levels were determined via Luminex assay, and the data for each sample is presented with the mean $+/$ - SEM for the group. B) The Luminex data were utilized to perform a receiver operating characteristic (ROC) curve, and the area under the curve (AUC) between controls and infected patients is presented. Note that serum IL-27 levels are highly diagnostic of $S$. aureus osteomyelitis. The dashed line represents a non-discriminatory test with equal sensitivity and specificity. In vitro cultures of (C) RAW264.7 cells and (D) primary murine bone marrow-derived macrophages were differentiated with PBS, IFN- $\gamma(50 \mathrm{ng} / \mathrm{ml})$ or IL-4 $(20 \mathrm{ng} / \mathrm{ml})$ to generate M0, M1 and M2 cells respectively, and then exposed to $S$. aureus $\mathrm{USA} 300(\mathrm{MOI}=10)$. These cultures were incubated for 24 hours, and IL-27 levels in the supernatants were assessed via ELISA. The data from each experiment are presented with the mean $+/-\mathrm{SD}$ for the group $(\mathrm{n}=3)\left({ }^{*} p<0.05,{ }^{* *} p<0.01\right.$, $* * * p<0.001 * * * * p<0.0001$, ANOVA). 
Figure 2
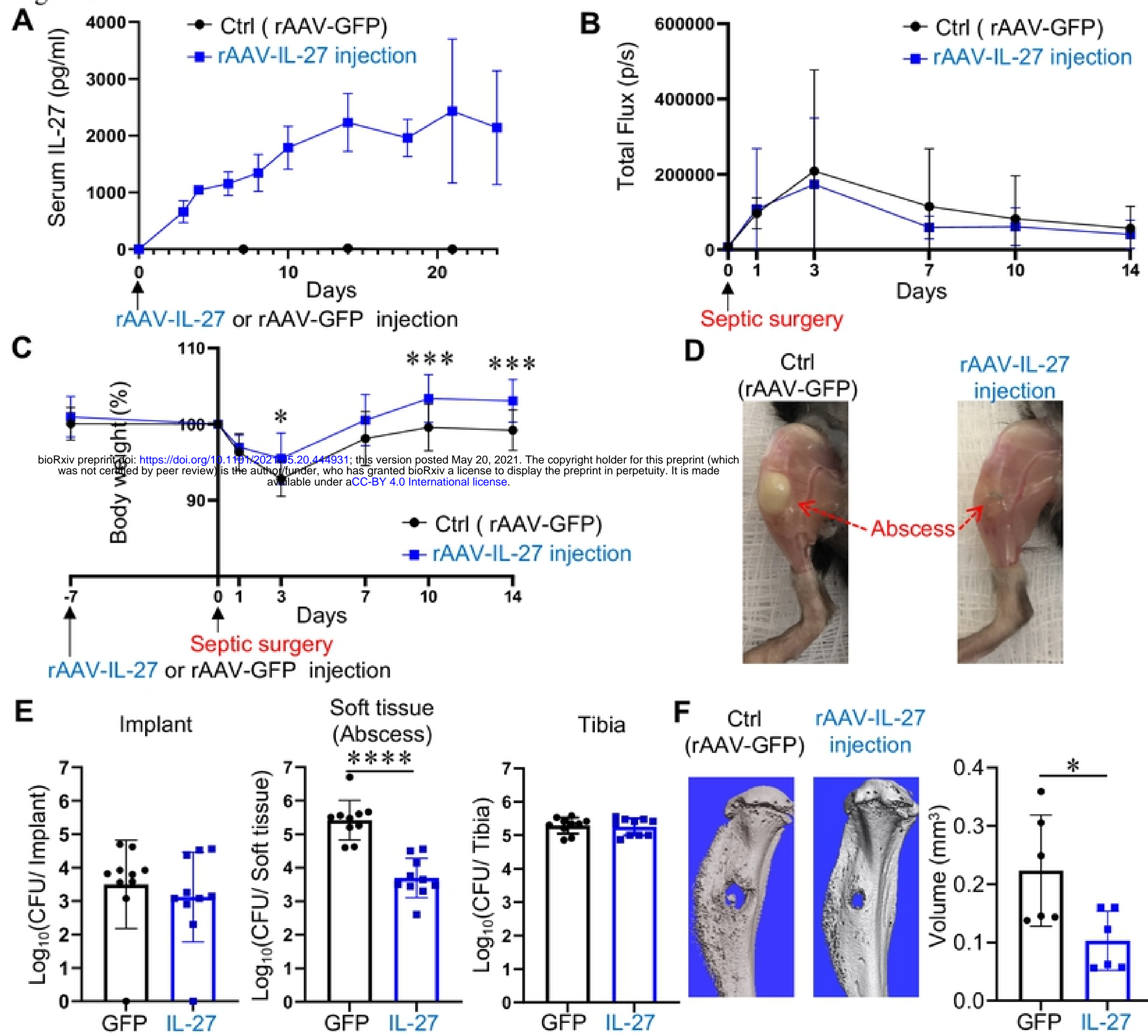

rAAV-IL-27
injection

Figure 2. Systemic IL-27 ameliorates surgical site soft tissue infection and osteolysis during S. aureus implantassociated osteomyelitis. (A) 8-week-old female C57BL/6 mice received $0.5 \times 10^{12}$ genome copies/mouse of rAAV-IL$27(n=3)$ or rAAV-GFP (control, $n=5)$ via intramuscular injection, and serum samples were collected longitudinally to assess IL-27 levels via ELISA. Exogenous IL-27 levels in sera are presented as the mean +/- SD. (B-F) A separate cohort of these mice were intramuscularly injected with rAAV-IL-27 or rAAV-GFP $(n=16)$, and then challenged 7 days later with $5 \times 10^{5}$ CFU of USA300 LAC::lux on a contaminated transtibial pin as described in Materials and Methods. Longitudinal BLI (B) and animal weight (C) were obtained on days $0,1,3,7,10 \& 14$, and the data are presented as the mean $+/-\mathrm{SD}\left({ }^{*} p<0.05\right.$ on Day $3,{ }^{* * *} p<0.001$ on Day 10 and 14 , two-way ANOVA). (D) Photographs of the infected tibiae were obtained on day 14 , and representative images of the large vs. small draining abscesses observed in the rAAV-GFP and rAAV-IL-27 treated mice respectively are shown. The mice were euthanized on day 14, and the infected tibiae were harvested for CFU and micro-CT analyses. (E) CFUs from the implant, soft tissue and tibia were determined, and the data for each tibia are presented with the mean $+/-\mathrm{SD}$ for the group $(\mathrm{n}=10, * * * * p<0.0001, \mathrm{t}$ test). (F) Representative 3D renderings of the extensive peri-implant osteolysis and reactive bone formation in rAAV-GFP vs. rAAV-IL-27 treated tibiae are shown with the volumetric bone loss in the infected tibiae. Data are presented for each tibia with the mean $+/-\mathrm{SD}$ for the group $\left(\mathrm{n}=6,{ }^{*} p<0.05\right.$, t test). 
Figure 3

A

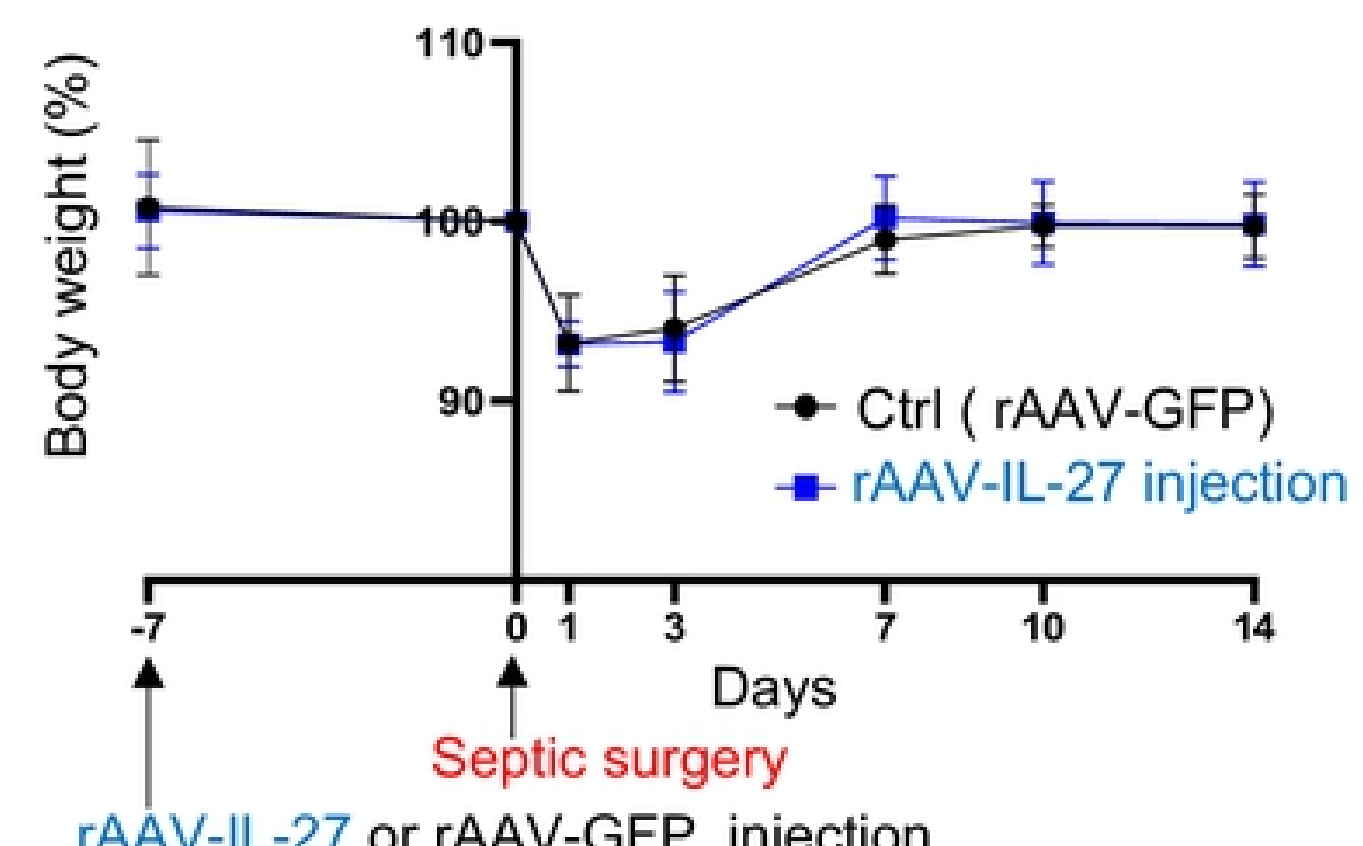

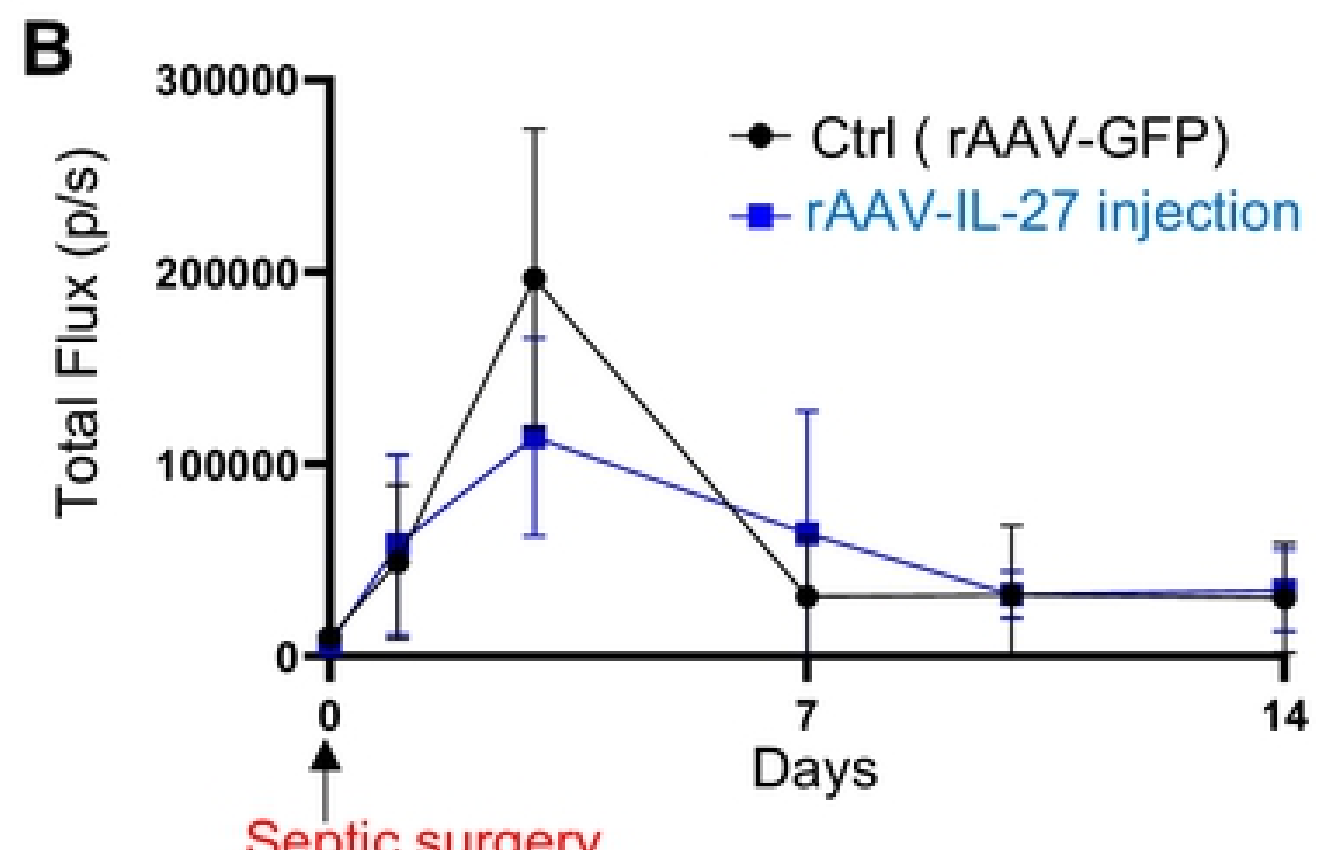

Septic surgery

C $\quad$ D 1 D 1 inplant

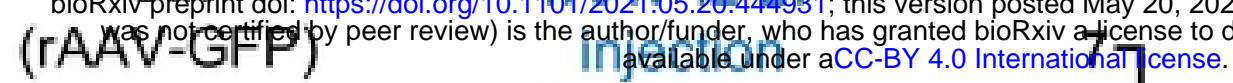
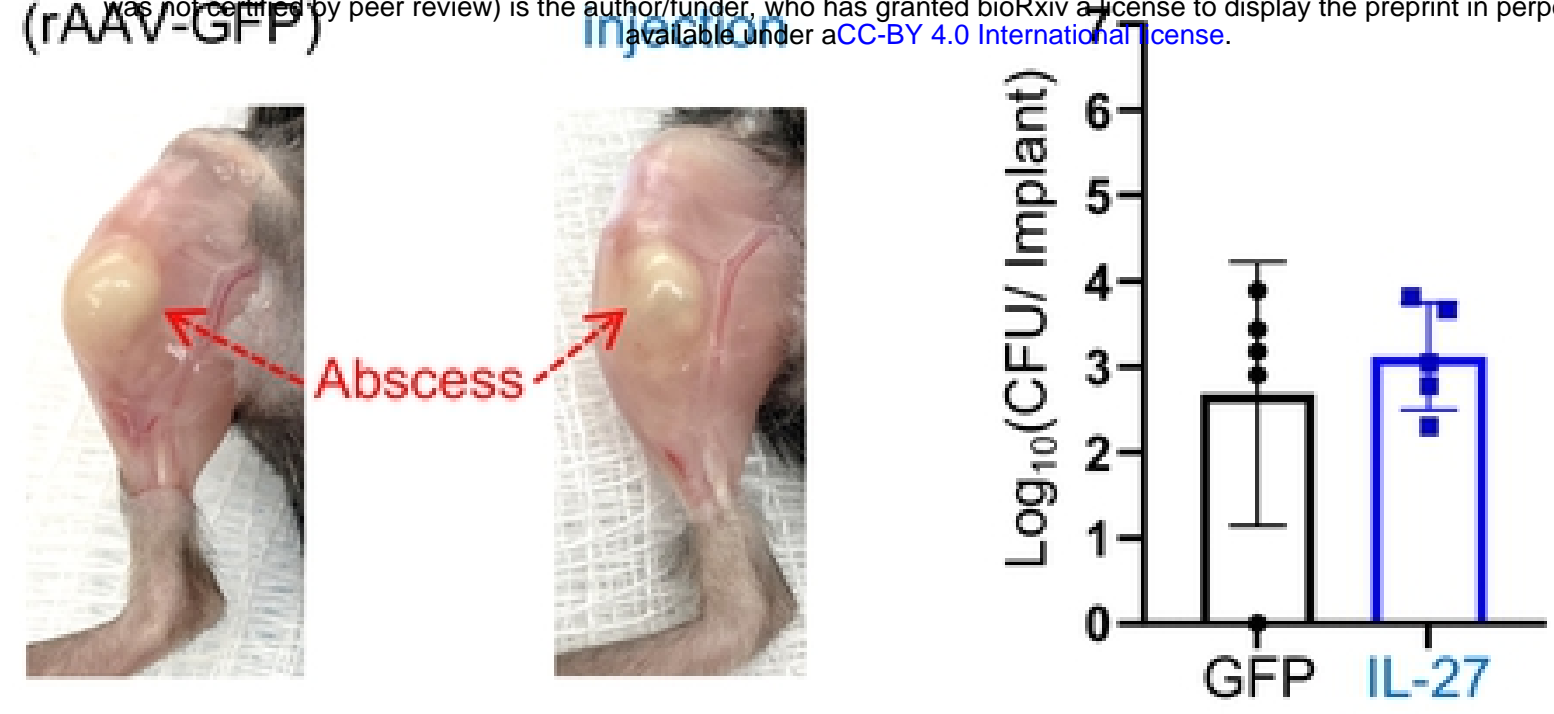

Soft tissue

(Abscess)

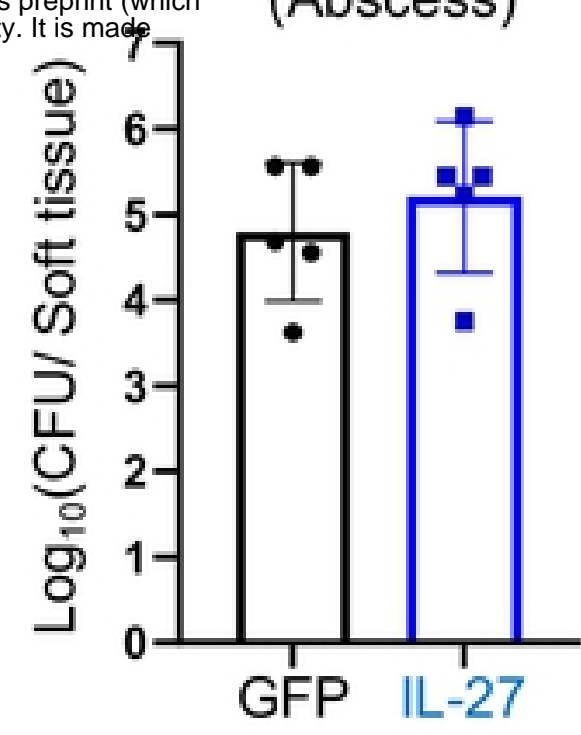

Tibia

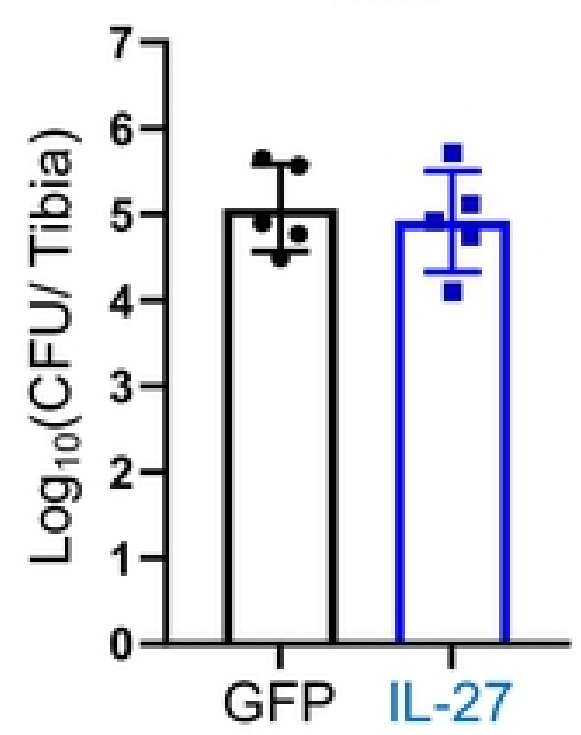

Figure 3. Absence of systemic IL-27 effects on implant associated osteomyelitis in IL-27R $\alpha^{-/}$mice. Female IL-27R $\alpha^{-/}$mice (C57BL/6 background) were intramuscularly injected with rAAV-IL-27 or rAAVGFP and then challenged with a MRSA (USA300 LAC::lux) contaminated transtibial implant as described in Figure 2. Animal weight (A) and BLI (B) were obtained on days $0,1,3,7,10 \& 14$, and the data are presented as the mean $+/$ - SD for the group $(n=5)$. (C) Representative photographs obtained on day 14 postsurgery, illustrate similar large draining abscesses in both groups. (D) CFUs from the implant, surgical site soft tissue, and tibia were determined after euthanasia on day 14 post-op, and data from each tibia are presented with the mean $+/-\mathrm{SD}$ for the group $(\mathrm{n}=5)$. No differences were observed between the experimental groups. 
Figure 4

A

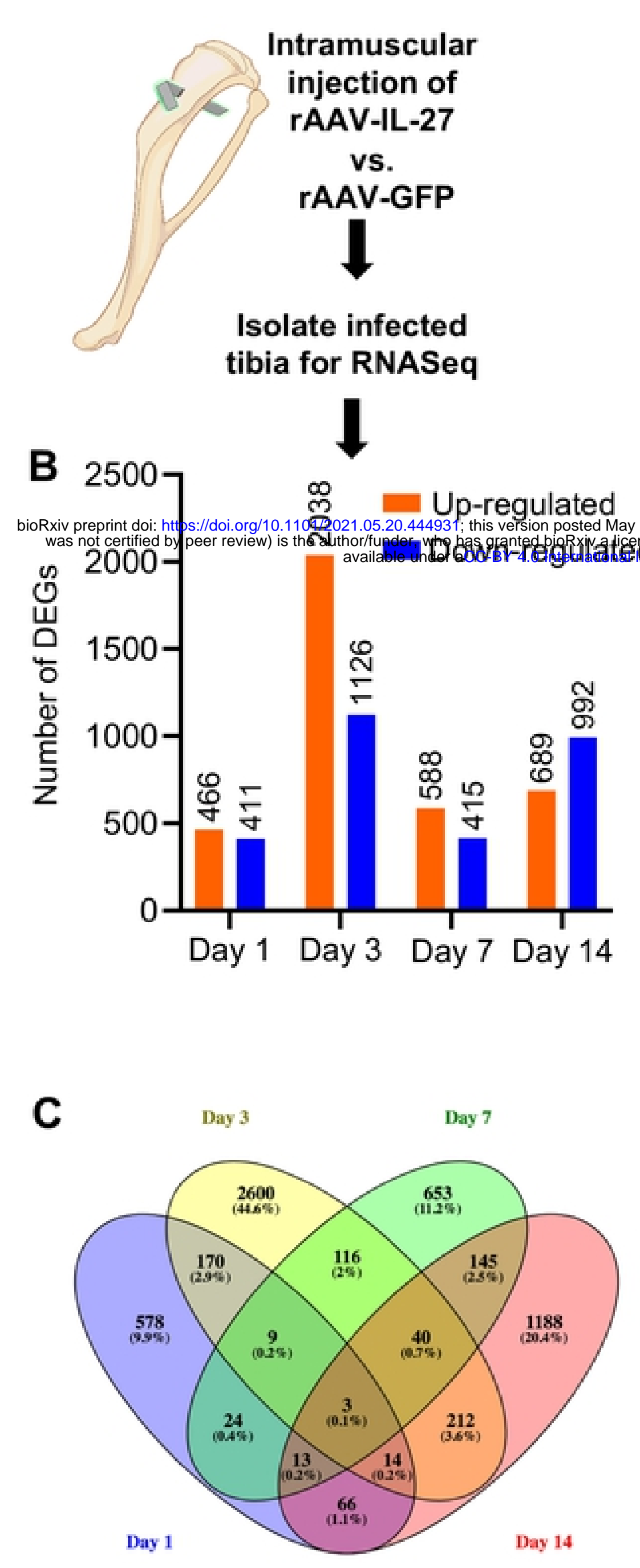

D

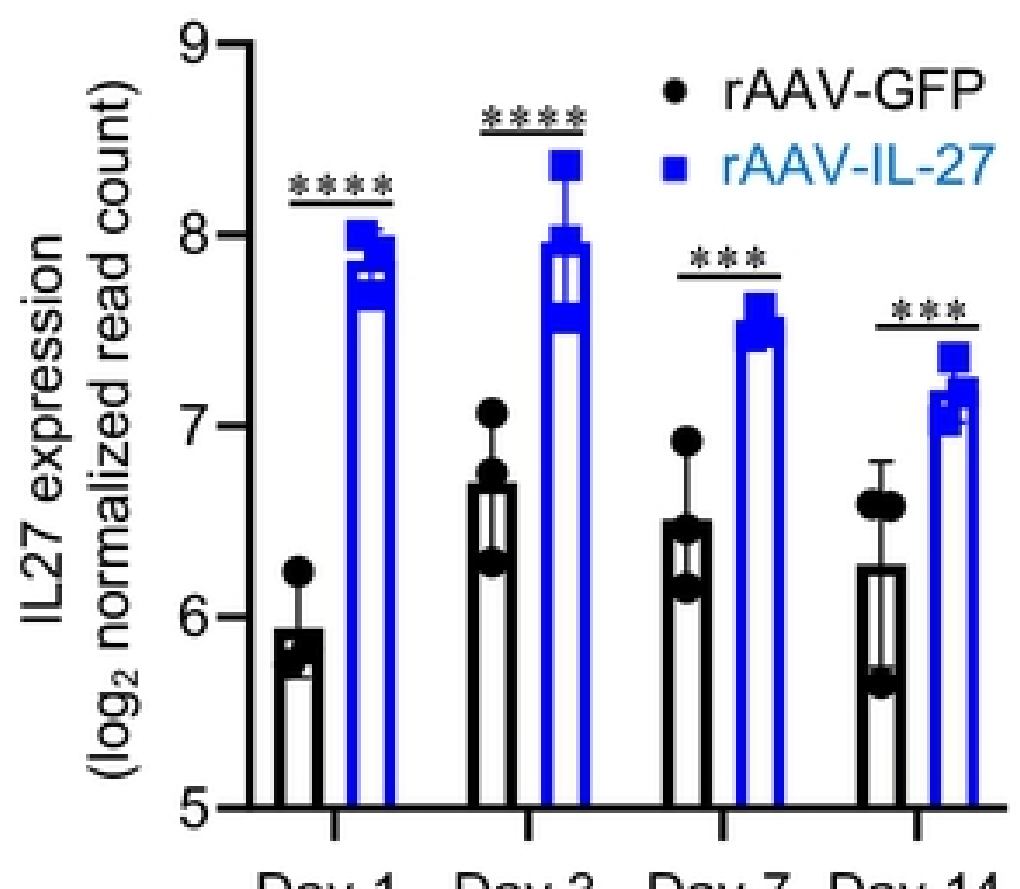

E

Day 1 Day 3 Day 7 Day 14

Day post surgery $\begin{array}{lllll}20,2021 . \text { The copyright holder for this preprint (which } & \mathbf{1} & \mathbf{3} & \mathbf{7} & \mathbf{1 4}\end{array}$

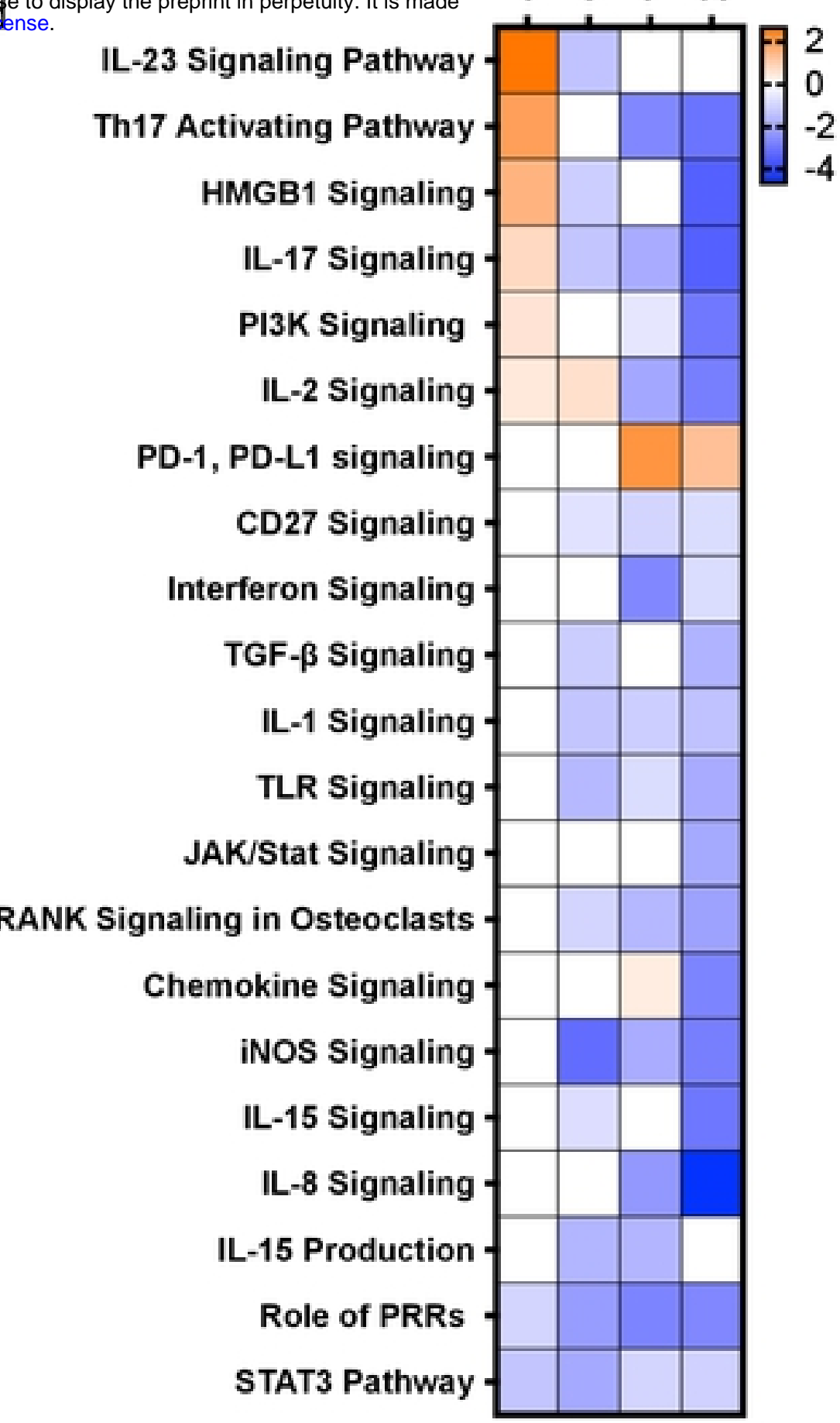


Figure 4

Figure 4. Identification of systemic IL-27 affected pathways during the establishment of implant-associated osteomyelitis via bulk RNA sequencing of $S$. aureus-infected tibia. (A) MRSA-infected tibiae were collected on days $1,3,7$ and 14 post-septic surgery for bulk RNA sequencing $(\mathrm{n}=3)$, and differential gene expression between rAAV-IL-27 and rAAV-GFP treated mice were evaluated using DESeq2-1.22.1 R/Bioconductor package. (B) The number of significant differentially up-regulated and down-regulated genes in mice treated with rAAV-IL-27 on each day is shown. (C) Venn diagram analyses showing the overlap of DEGs across days 1, 3, 7 and 14 postseptic surgery in in mice treated with rAAV-IL-27 vs. rAAV-GFP, respectively. (D) Expression of IL27 in infected tibiae was upregulated in mice treated with rAAV-IL-27, suggesting a positive feedback effect. $\left(* * * * p<0.0001\right.$ on days $1 \& 3,{ }^{* * *} p<0.001$ on days $\left.7 \& 14\right)$. (E) Ingenuity Pathway Analysis (IPA) was utilized to identify canonical pathways of DEGs between rAAV-IL-27 vs. rAAVGFP treated mice over time. Significant association $\left({ }^{*} p<0.05\right)$ were calculated based on the Fisher's right tailed exact test. The orange and blue colored bars indicate predicted pathway activation or

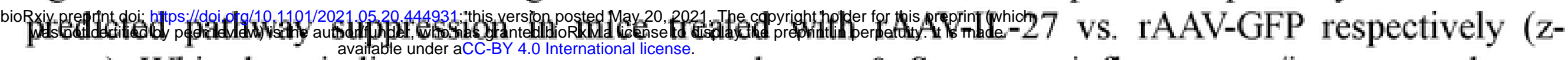
score). White bars indicate $z$-score at or very close to 0 . Some pro-inflammatory/immune pathways including IL-17 signaling, Th17 activating pathway, IL-2 signaling were activated in mice treated with rAAV-IL-27 on day 1 following infection. On the other hand, these pathways and others (e.g.) were suppressed at later time points. Moreover, immunosuppressive PD-1/PD-L1 signaling pathway was upregulated at later time points. These result indicate that IL-27 is a biphasic cytokine that activates pro-inflammatory/immune pathways early upon $S$. aureus infection, and then suppresses them late to prevent tissue damage and cytokine storm. 
Figure 5

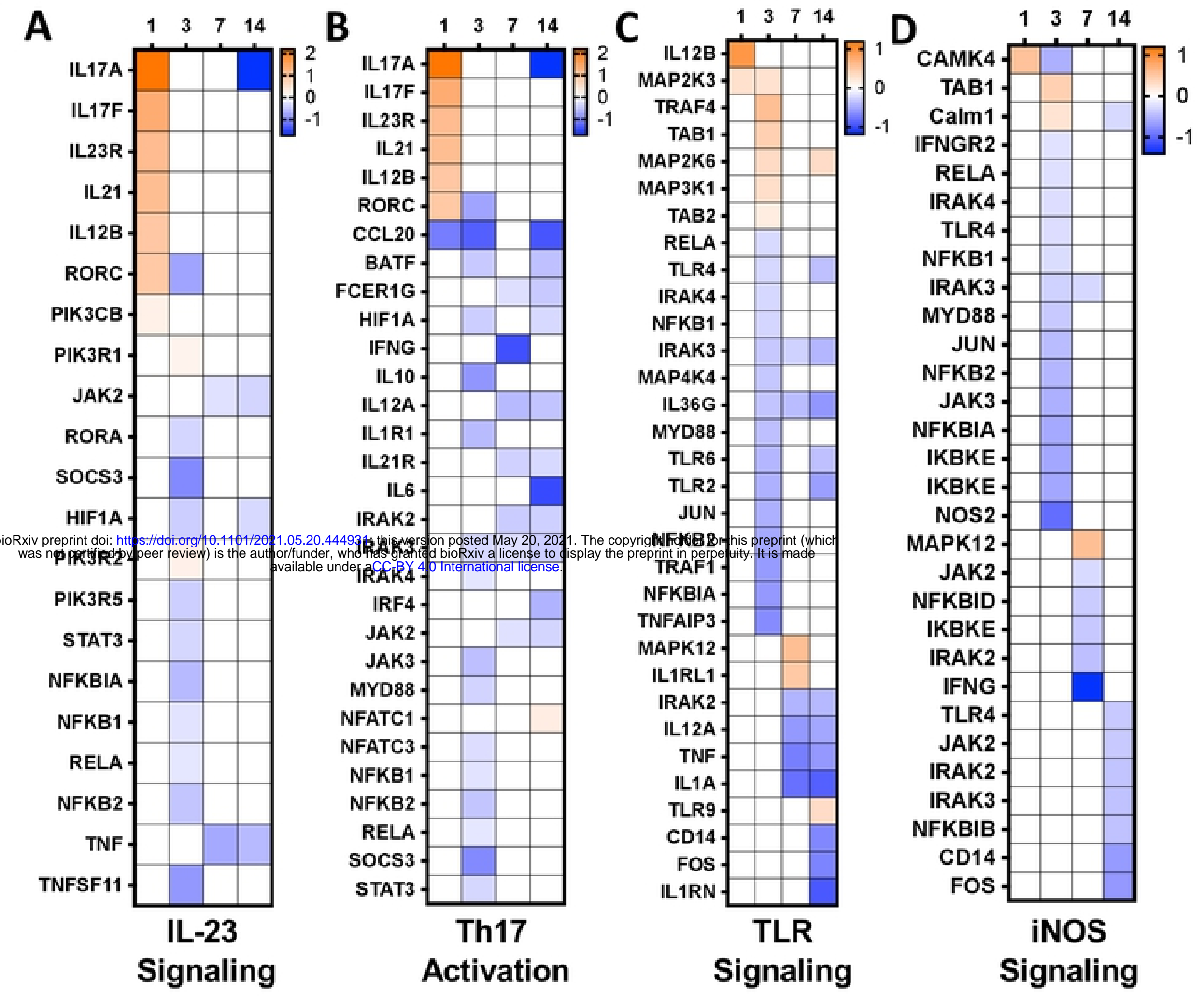

Figure 5. IL-27 up-regulated pro-inflammatory cytokines during the initiation of implant-associated $S$. aureus osteomyelitis and their down-regulation during chronic infection. DEGs in the (A) IL-23, (B) Th17, (C) TLR, and (D) iNOS signaling pathways are shown with $\log _{2}$ fold change on each day as heatmaps. The orange and blue colored bars indicate up-regulation or down-regulation in mice treated with rAAVIL-27 vs. rAAV-GFP, respectively ( $\log _{2}$ fold change, $p<0.05$ ). Pro-inflammatory cytokine coding genes such as IL17A, IL17F, IL21, and IL12B were upregulated on day1 post-surgery. In contrast, pro-inflammatory cytokine genes such as $I L 17 A, I L 12 A, T N F$, and $I L 6$ were downregulated on day- 14 . 
Figure 6

A

RANK Signaling in Osteoclast

AAV-GFP control

AAV-IL-27

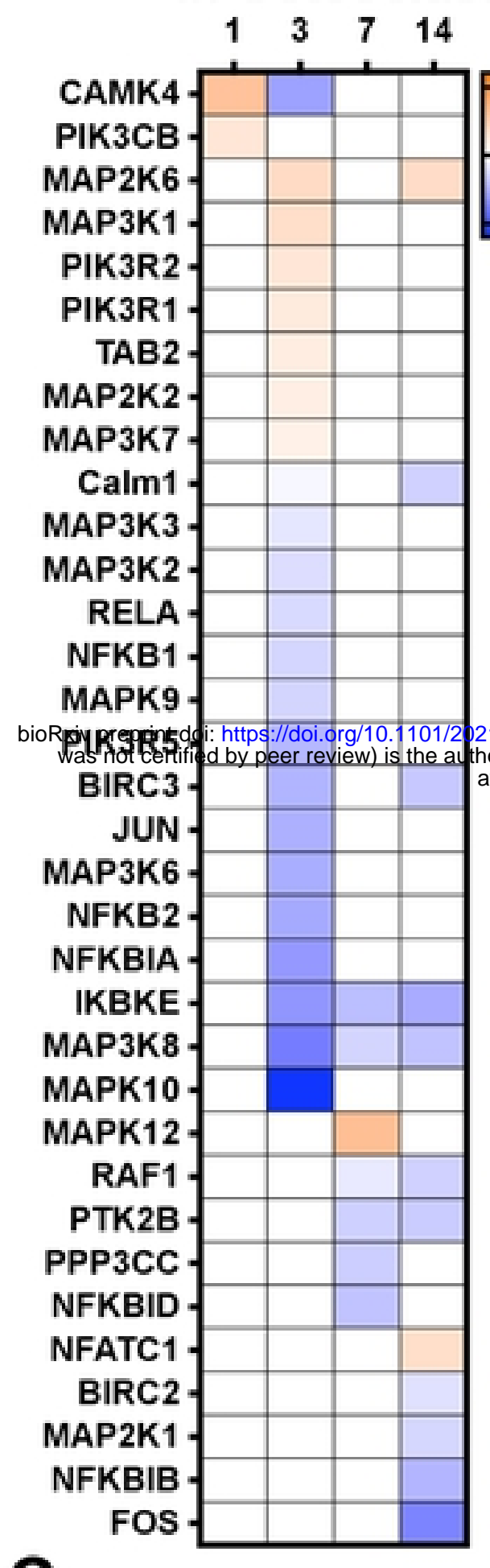

Cortical bone

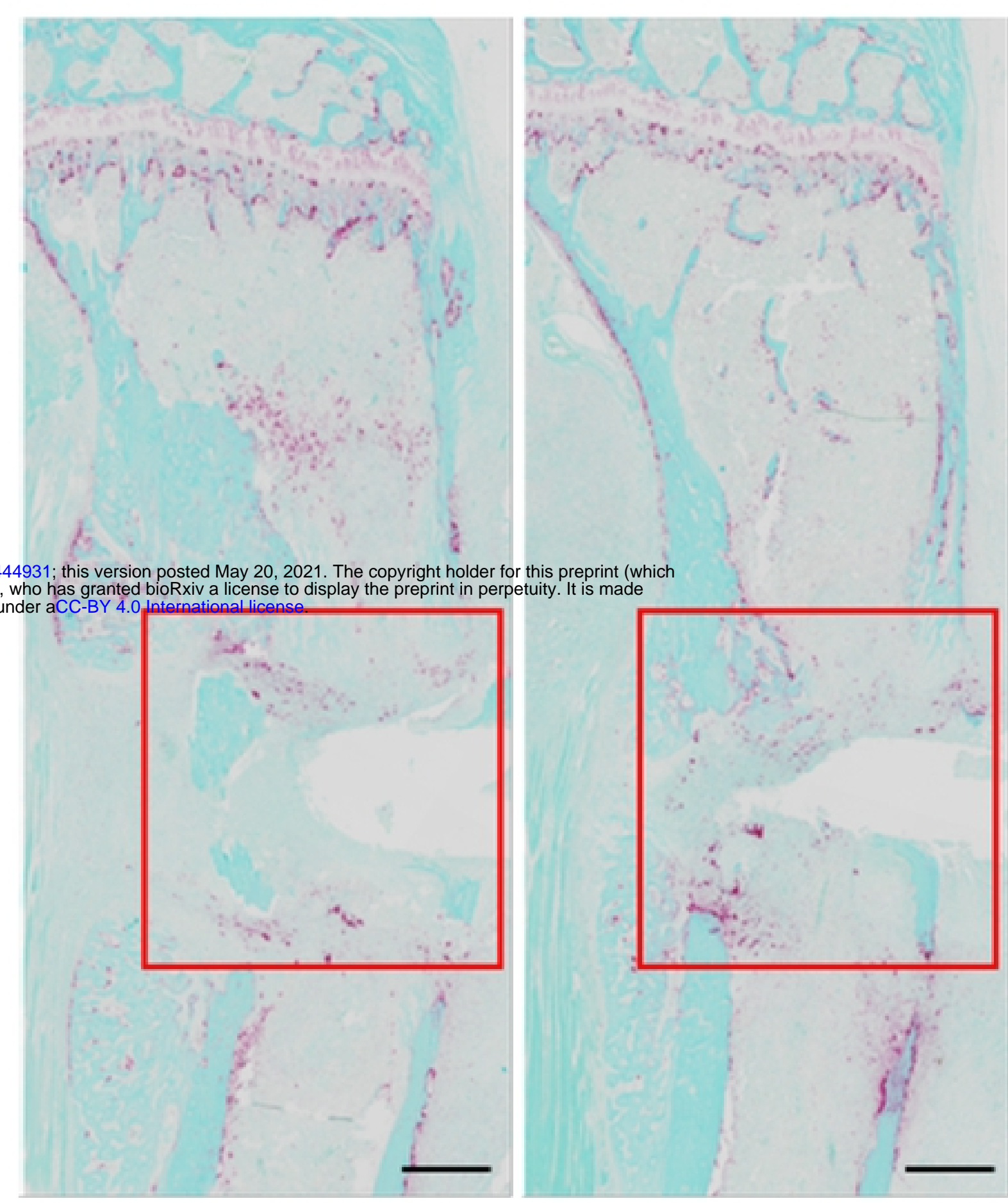

Trabecular bone

Implant sites
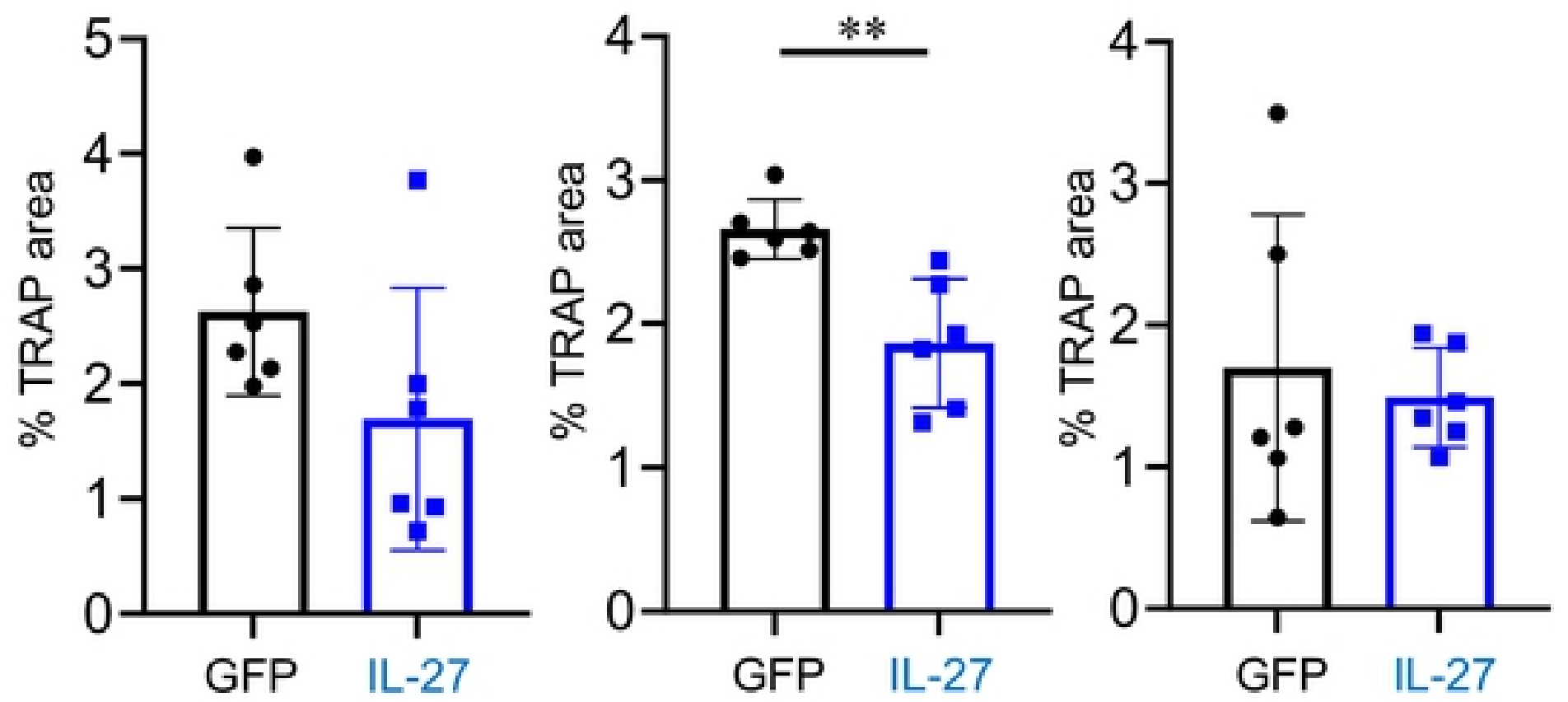

Figure 6. Systemic IL-27 inhibits osteoclast formation during implant-associated osteomyelitis. (A) Data from the IPA in Figure 4 are shown to illustrate the decrease in RANK signaling in rAAV-IL27 vs. rAAV-GFP treated infected tibiae on days 3, 7 and 14. (B) To confirm the gene expression data, tibiae from the mice described Figure 2 were processed for histology. Representative $2 \mathrm{x}$ images of tibia sections stained for TRAP (red/purple) are shown (scale bars $=500 \mu \mathrm{m})$. (C) $\%$ TRAP-stained area was quantified within the cortical bone regions, trabecular bone regions, and implant sites (red box), and the data are presented for each tibia with the mean $+/-\mathrm{SD}$ for the group $\left(\mathrm{n}=6,{ }^{*} * p<0.05, \mathrm{t}\right.$ test). 
Figure 7

A

At the onset of

S. aureus osteomyelitis

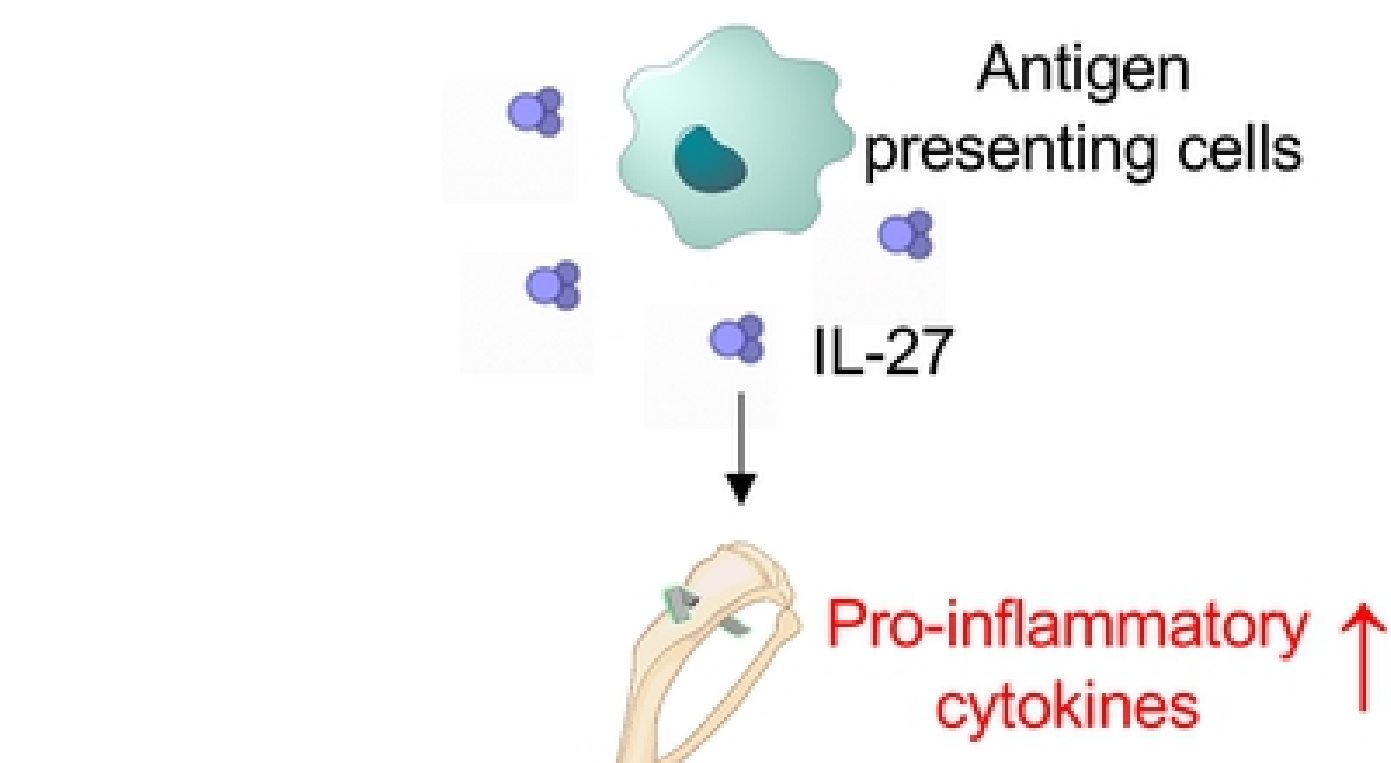

bioRxiv preprint doi: https://doi.org/10.1101/2021.05.20.444931; this version posted May 20, 2021. The copyright holder for this preprint (which was not certified by peer review) is the author/funder, who has granted bioRxiv a license to display the preprint in perpetuity. It is made

$$
\begin{aligned}
& \text { available under aCC-BY } 4.0 \text { International license. } \\
& \text { acen }
\end{aligned}
$$

Enhanced bacteria killing by neutrophils and macrophages
B At later stage of

S. aureus osteomyelitis

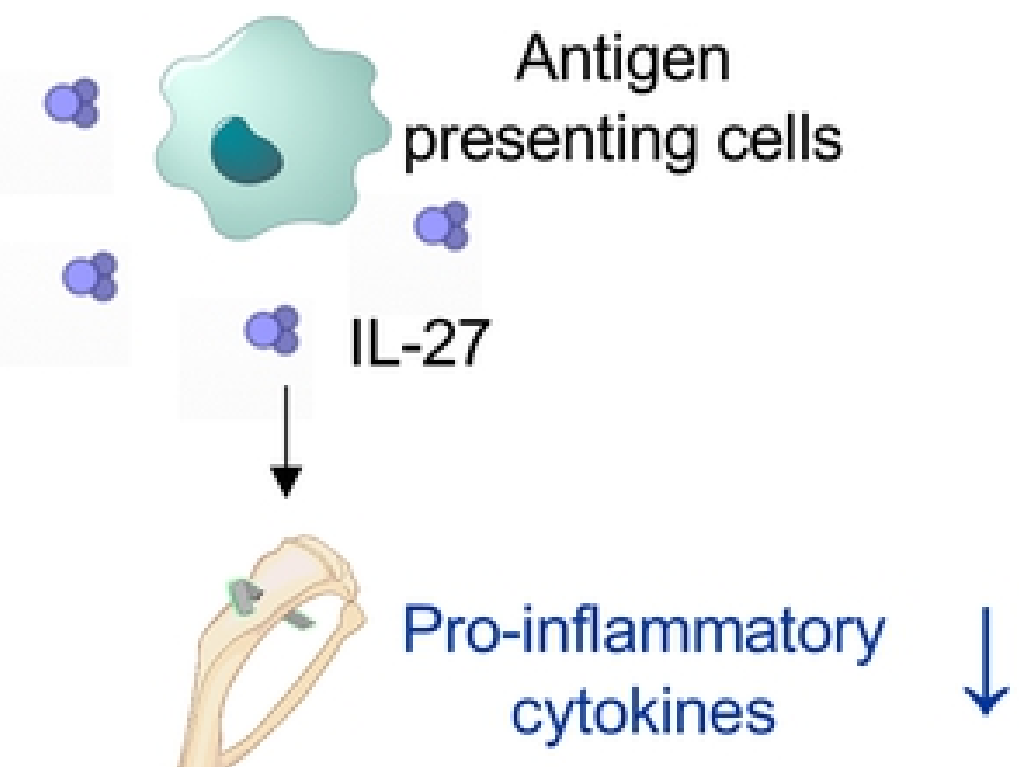

Osteoclastogenesis

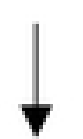

Prevention of

cytokine storm and osteolysis

Figure 7. Schematic model of IL-27 mediated immune regulation during $S$. aureus osteomyelitis. A schematic model of IL-27-mediated immune regulation during $S$. aureus osteomyelitis is shown in which IL-27 promotes host immune reaction against $S$. aureus osteomyelitis by regulating its reported diverse immune-activation and immune-suppression effects in a time dependent manner. (A) At the onset of $S$. aureus osteomyelitis, IL-27 promotes production of pro-inflammatory cytokines, leading to enhanced bacteria killing by macrophages and neutrophils. (B) In contrast, at later stages of $S$. aureus osteomyelitis following acute reaction, IL-27 decreases production of pro-inflammatory cytokines and osteoclastogenesis, which prevents cytokine storm and osteolysis. 
Supplemental Figure 1

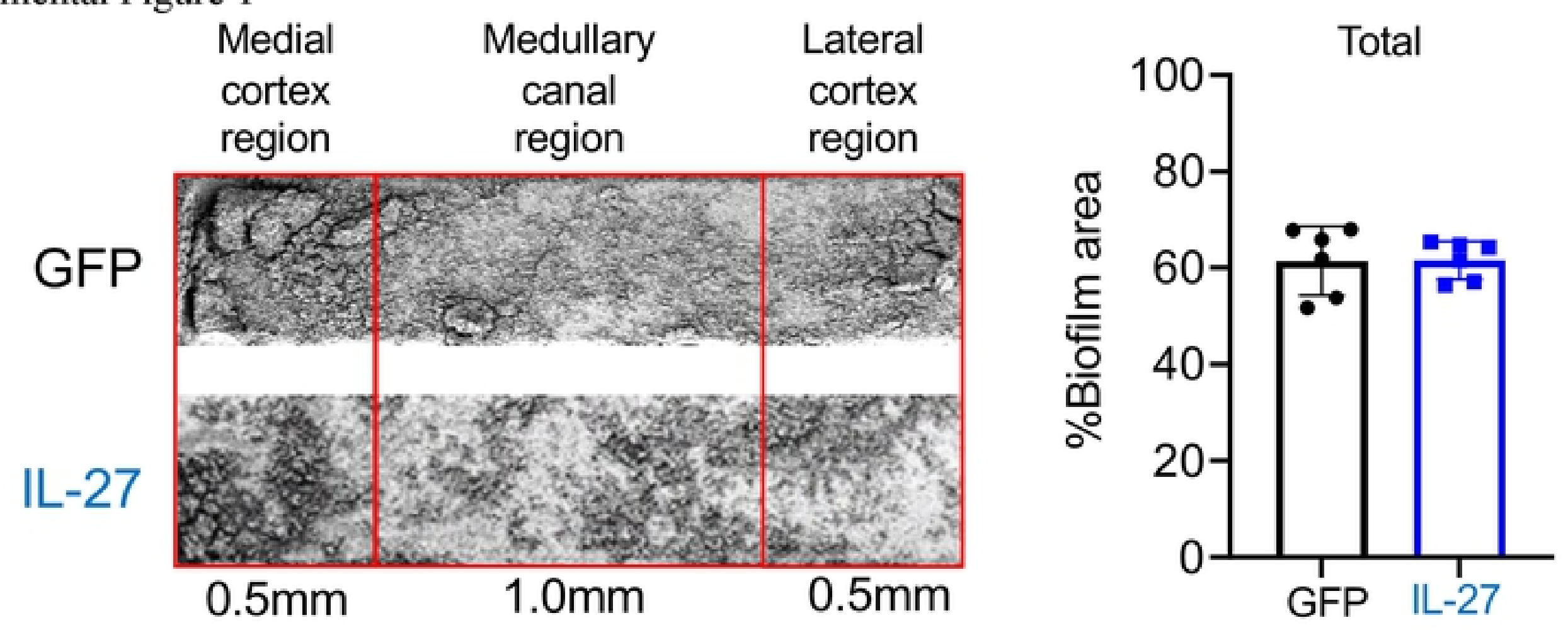

Medial

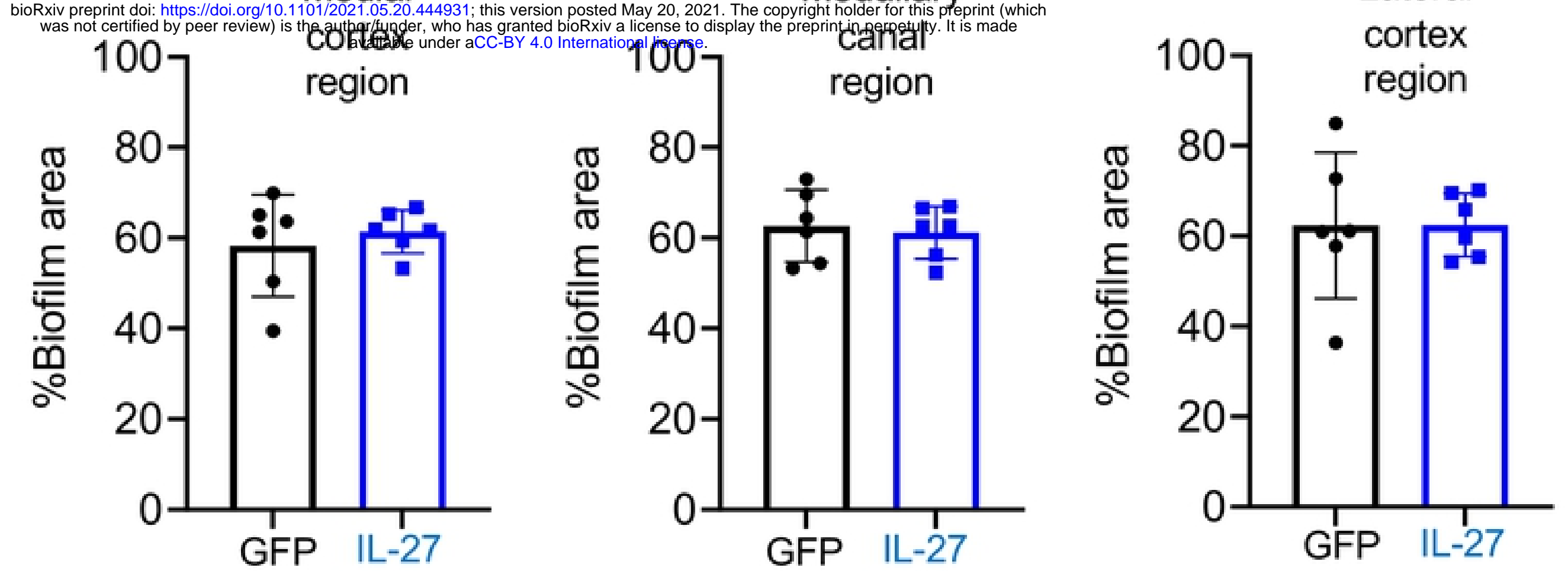

Supplemental Figure 1. Systemic IL-27 does not affect biofilm formation on the implant during $S$. aureus implant-associated osteomyelitis in vivo. Mice were intramuscularly injected with rAAV-IL-27 or rAAV-GFP and then challenged with a MRSA (USA300 LAC::lux) contaminated trans-tibial implant as described in Figure 2. Biofilm formation on the implant was determined via SEM processing and imaging after euthanasia on day 14 post-op. No difference was detected in \%biofilm formation area on implant between rAAV-IL-27 and rAAV-GFP challenged mice $(n=6)$. 


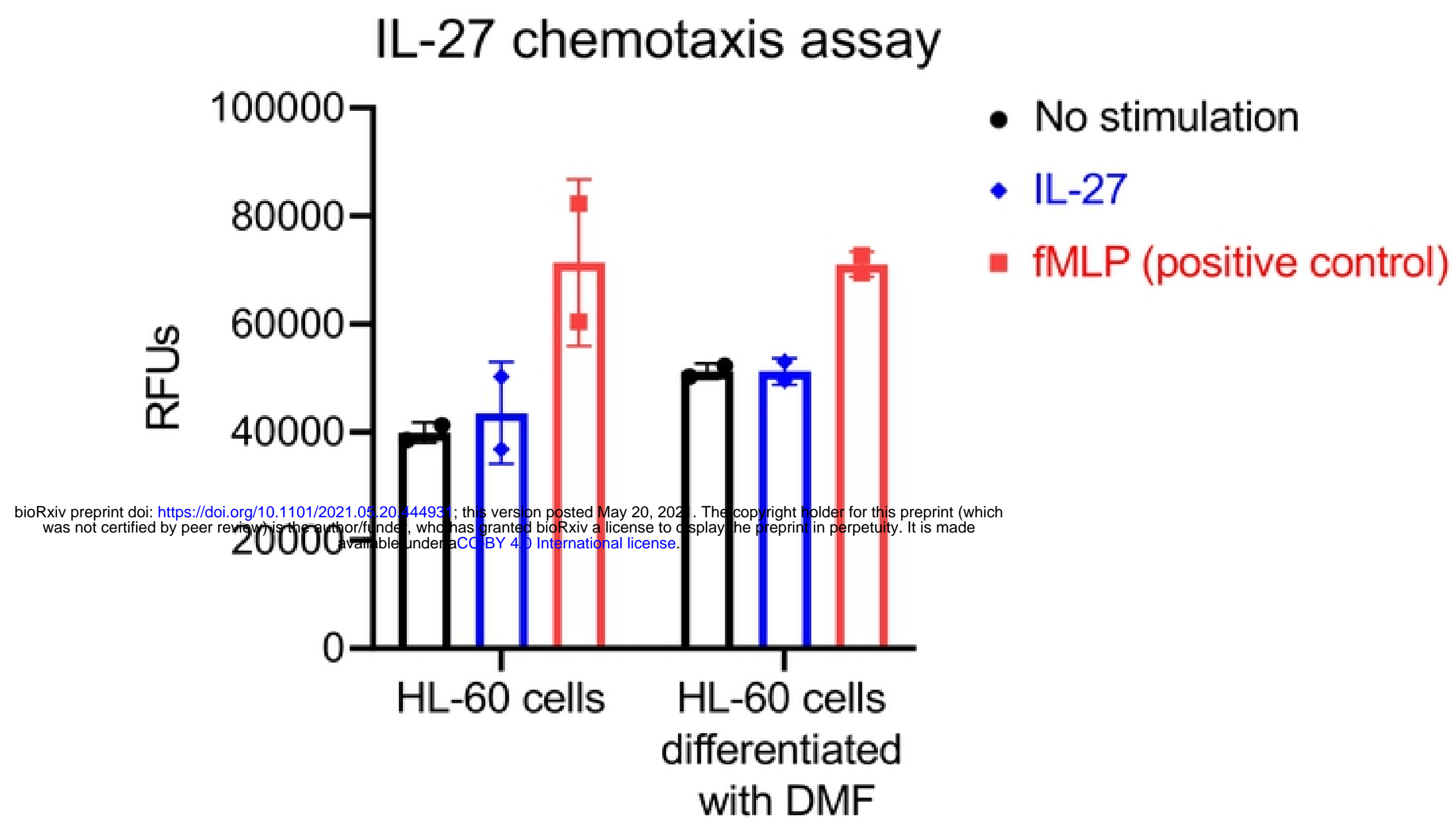

Supplemental Figure 2. IL-27 does not stimulate myeloid cell chemotaxis. HL-60 cells were differentiated 7 days in the presence or absence of dimethylformamide (DMF) $(9 \mu \mathrm{g} / \mathrm{ml}$ ), and then placed in Boyden chambers. Cell culture media with or without IL-27 or fMLP (positive-control) was placed in the well below the chamber and incubated for 1 hour. Subsequently, cells which migrated in each well were stained with fluorescent dye and signal intensity was evaluated using a fluorescent plate reader $(\mathrm{n}=2)$. No difference in chemotactic activity of granulocytes was observed between the experimental groups. 
Supplemental Figure 3

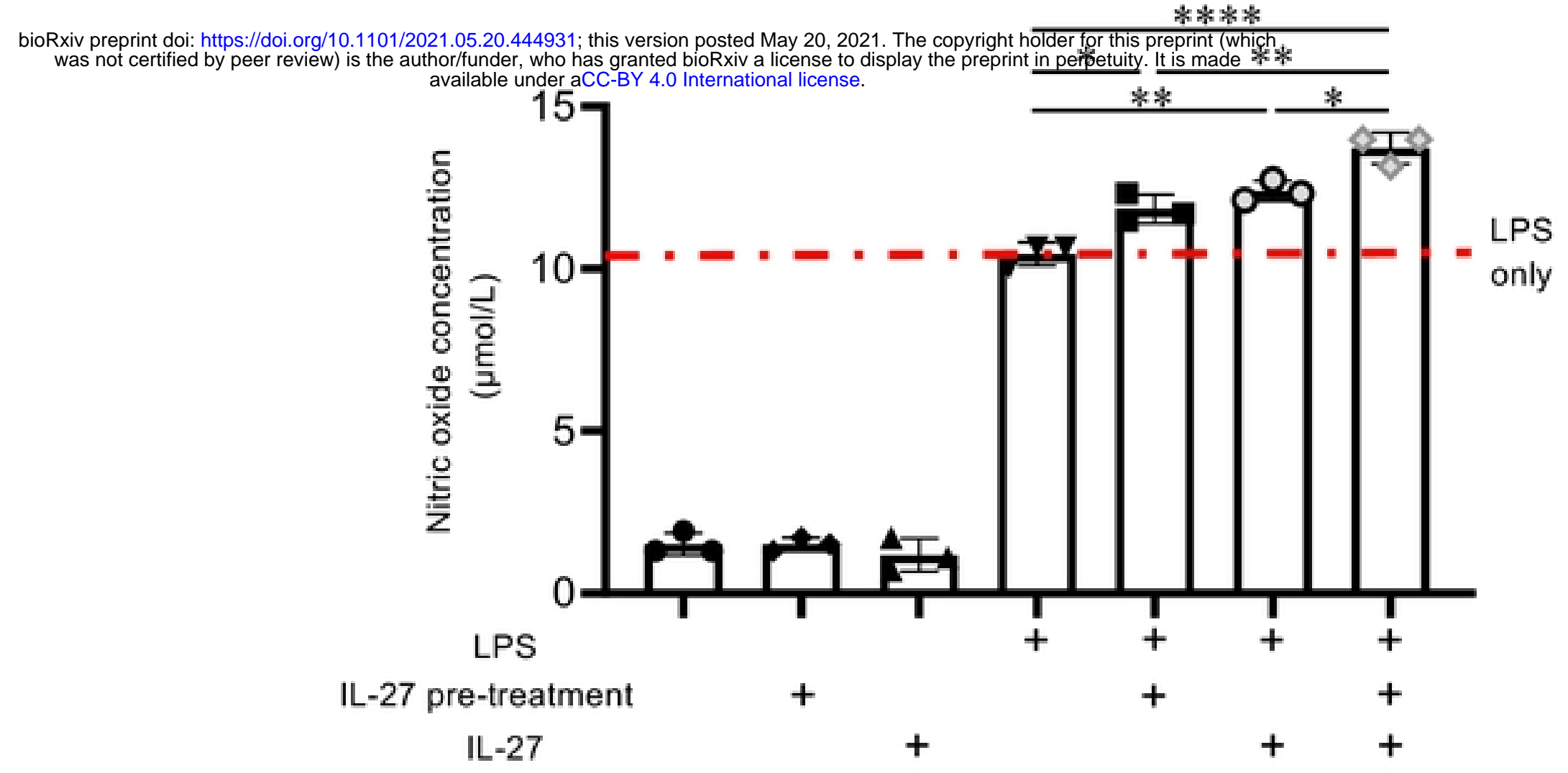

Supplemental Figure 3. IL-27 enhances LPS-induced NO- production by macrophage cultures. Primary bone marrow derived murine macrophages were pretreated with PBS or IL-27 (50 ng/ml) for 24 hours, and then stimulated with LPS $(100 \mathrm{ng} / \mathrm{ml})$ in the presence or absence of IL-27 $(50 \mathrm{ng} / \mathrm{ml})$ for 24 hours. Nitrite levels in the culture supernatant was determined via Griess reaction assay, and the data from each experiment are presented with the mean $+/$ SD for the group $\left(\mathrm{n}=3,{ }^{*} p<0.05, * * p<0.01\right.$, $* * * * p<0.0001$ by one-way ANOVA). 


\section{Supplemental Table 1}

Supplemental Table 1. Top regulatory effect networks of DEGs in mice treated with rAAV-IL-27 versus rAAV-GFP

\begin{tabular}{|c|c|c|c|c|c|}
\hline & & Consittency score & Regulators & Target molecules in dataset & Fuctions \\
\hline \multirow[t]{2}{*}{ Day 1} & 1 & 14.432 & $\begin{array}{l}\text { HSP90B1, HBB, EGR2, BCL2, } \\
\text { TNFRSF4, LTA }\end{array}$ & $\begin{array}{l}\text { BCL2A1, CXCL13, CCL20, CXCL9, CXCL6, IL7R, } \\
\text { AIF1, IL21, IL17A, IL12B, VCAM1, IL17F, RORC, } \\
\text { GZMB }\end{array}$ & $\begin{array}{l}\text { Inflammation of body cavity, Inflammation of organ, Inflammation of } \\
\text { absolute anatomical region, Inflammation of respiratory system } \\
\text { conponent: Predicted activation }\end{array}$ \\
\hline & 2 & 8.05 & NRIH & IL12B, PTGES, MERTK, ABCG1, CD5L & $\begin{array}{l}\text { Inflammation of absolute anatomical region Inflammntion of body } \\
\text { cavity, Inflammation of respiratory system component, Cell death of } \\
\text { immune cells, Apoptosis of blood cells: Predicted activation }\end{array}$ \\
\hline \multirow[t]{2}{*}{ Day 3} & 1 & 11.333 & $\begin{array}{l}\text { MYD88, TICAM1, GFII, IL33, } \\
\text { IGE,NFKB, NFKB1, NOD2, FOS, } \\
\text { IKBKB }\end{array}$ & $\begin{array}{l}\text { ILIR1, EDNRB, HDC, IL10, ICAM1, MDM2, SMAD3, } \\
\text { C5, GRN }\end{array}$ & Increased levels of creatinine: Predicted suppression \\
\hline & 2 & 10.436 & $\begin{array}{l}\text { JUNB, SMARCA4, STAT3, } \\
\text { TNFSF11, IL1, IL1A, OSM, CHUK, } \\
\text { IL6R, CD40LG, TGFB2, RELA }\end{array}$ & $\begin{array}{l}\text { IF116, CSF3, NOS3, IL11, IGF2, TNFRSF11B, RB1, } \\
\text { SMAD3, NOTCH1, HES1 }\end{array}$ & Increased activation of alkaline phosphatase: Predicted suppression \\
\hline \multirow[t]{2}{*}{ Day 7} & 1 & 3.175 & TICAMI & $\begin{array}{l}\text { IL12A, IRF7, CCL5, IFNG, TNF, IL1A, DDX58, } \\
\text { CH25H, FPR1, ICAM1, CCRL2, IKBKE }\end{array}$ & Cell movement of blood cells: Predicted suppression \\
\hline & 2 & 3.175 & TICAMI & $\begin{array}{l}\text { IL12A, IRF7, CCL5, IFNG, TNF, IL1A, DDX58, } \\
\text { CH25H, FPR1, ICAM1, CCRL2, IKBKE }\end{array}$ & Leukocyte migration Predicted suppression \\
\hline \multirow{2}{*}{\multicolumn{2}{|c|}{ 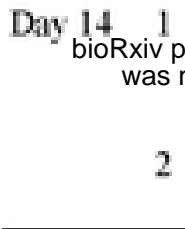 }} & $\begin{array}{l}\text { 4.025 } \\
\text { eprint doi: https://doi.or } \\
\text { ot certified by peer revi }\end{array}$ & $\begin{array}{l}\text { II.1B } \\
\text { g.11.1101/2021.05.20.444931; this version } \\
\text { w) is the authorffunder, who has granted bi } \\
\text { available under aCC-BY } 4.0 \text { in }\end{array}$ & 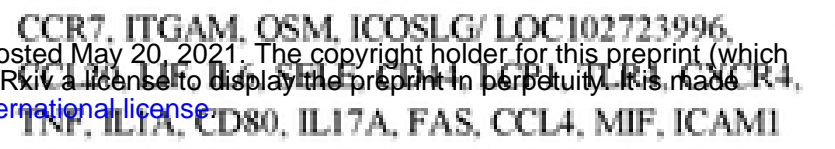 & Adhesion of mononselear leukocytes: Predicted suppression \\
\hline & & 3.873 & IL17A & $\begin{array}{l}\text { TGFA, HBEGF, LIF, COL1A1, SLC2A1, IL6, FOS, } \\
\text { TLR4, AREG. TNF, ILIA. TIMP1, CSF3, FAS. IL36G }\end{array}$ & Proliferation of connective tissue cells: Predicted suppression \\
\hline
\end{tabular}

